\title{
WestVirginiaUniversity
}

THE RESEARCH REPOSITORY @ WVU

Graduate Theses, Dissertations, and Problem Reports

2015

\section{Effects of Protein Supplementation on Parasitism and Growth in Grazing Lambs}

Crista Crawford

Follow this and additional works at: https://researchrepository.wvu.edu/etd

\section{Recommended Citation}

Crawford, Crista, "Effects of Protein Supplementation on Parasitism and Growth in Grazing Lambs" (2015). Graduate Theses, Dissertations, and Problem Reports. 5409.

https://researchrepository.wvu.edu/etd/5409

This Thesis is protected by copyright and/or related rights. It has been brought to you by the The Research Repository @ WVU with permission from the rights-holder(s). You are free to use this Thesis in any way that is permitted by the copyright and related rights legislation that applies to your use. For other uses you must obtain permission from the rights-holder(s) directly, unless additional rights are indicated by a Creative Commons license in the record and/ or on the work itself. This Thesis has been accepted for inclusion in WVU Graduate Theses, Dissertations, and Problem Reports collection by an authorized administrator of The Research Repository @ WVU. For more information, please contact researchrepository@mail.wvu.edu. 
Effects of Protein Supplementation on Parasitism and Growth in Grazing Lambs

\section{Crista Crawford}

Thesis submitted to the Davis College of Agriculture, Natural Resources and Design at West Virginia University in partial fulfillment of the requirements for the degree of

Master of Science in Animal Physiology

Scott A. Bowdridge, Ph.D., Chair

David P. Belesky, Ph.D.

Eugene E. Felton, Ph. D.
Division of Animal and Nutritional Sciences
Morgantown, WV
2015

Keywords: Sheep; Gastrointestinal Trichostrongylid Parasites; Protein;

Grazing 


\title{
Abstract \\ Effects of Protein Supplementation on Parasitism in Grazing Lambs
}

\author{
Crista Crawford
}

Controlling gastrointestinal nematode infection of sheep has become a challenge resulting from reduced anthelmintic efficacy. Previous data have indicated that grazing lambs supplemented with a $16 \% \mathrm{CP}$ ration at $1 \% \mathrm{BW}$ maintained growth comparable to lambs given anthelmintic despite greater infection. Thus the objective of the following studies was to determine the effects of bypass protein on fecal egg count reduction and post weaning growth in parasitized, grazing lambs. Experiment one utilized spring-born Suffolk crossbred lambs separated into 3 supplement groups: alfalfa pellets (AFP) (15\% CP), corn and soybean meal (CSM) (19\% CP) and corn, soybean meal and fish meal (CFM) (19\% CP). All animals were supplemented at 1\% average body weight (BW) except AFP animals which were supplemented at $1.28 \%$ average BW to account for lower supplemental CP. Animals were grazed on small paddocks for a maximum of 3 days. Fecal egg count (FEC) was significantly lower for the AFP and CFM animals compared to CSM supplemented lambs. FAMACHA scores were reduced by 1.3 in CFM lambs. Average daily gain (ADG) was also significantly affected as lambs supplemented with CFM was significantly higher than gain of lambs receiving AFP; with CSM being intermediate. Fish meal is known to have higher oil content, and perhaps lower FEC was a result of oil differences. To test this hypothesis, January-born Suffolk and Dorset lambs were randomly assigned to one of three treatment groups: corn and soybean meal (CSM), corn, soybean and fish meal (CFM) and corn, soybean meal and fish oil (CFO) all at 19\% CP. Animals were supplemented at 1\% average $\mathrm{BW}$. Animals were kept in a raised floor barn during a transition period where they were trickle infected with Haemonchus contortus larvae. After the transition period animals were moved to pasture where they grazed small paddocks for 3 days. FEC resulted in a tendency $(P=0.1103)$ for differences between groups. Further pairwise comparisons indicated that FEC of CFM supplemented lambs was lower than CSM but not different than CFO. Packed cell volume (PCV) was significantly higher for the $\mathrm{CFO}$ animals although all groups were within a normal range. No differences in gain were observed. These data indicate that supplementing grazing lambs with a rumen bypass protein source $(\mathrm{CFM})$ has the potential to reduce FEC while maintaining acceptable gain on pasture. 


\section{Acknowledgements}

I would like to thank my advisor, Dr. Scott Bowdridge for leading me through this whirlwind journey. Not only has he taught me to be a better scientist by asking the right questions, but also to become better stockman and constantly pushing me to do more with the everyday management of the WVU sheep flock. With his encouragement along with my committee and Dr. Mata-Padrino, I can take on anything the small ruminant industry has to throw at me.

This study would not have been possible without all the hard work from my wonderful labmates. Not only did they sacrifice their time and bodies to the sheep, they provided endless hours of entertainment in the office. My labmates were the greatest support system I could have asked for always being there with a listening ear or a helping hand. I would also like to personally thank Rebecca Leach for saving my second project after I was injured. I would have never finished without her willingness to take on such a big project all by herself.

Moving to West Virginia was one of the toughest things I've ever done, but Jenkins and Schaffer family welcomed me with open arms. They became my adoptive family and a place of refuge when I'd have enough of the sheep. I'm not sure what I would have done without their constant love and support.

Lastly, my friends and family have been there for me through every waking second of my graduate career. My friends made sure I never missed out on anything important and were always there for me no matter what. My parents provided love and encouragement throughout this journey that was very new for all of us. I love you all and thank you for helping me make it this far on life's crazy journey. 


\section{Table of Contents}

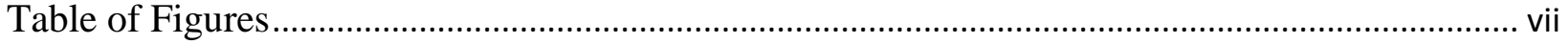

List of Tables ............................................................................................................................. viii

Chapter 1: Gastrointestinal Nematodes in Sheep..........................................................................

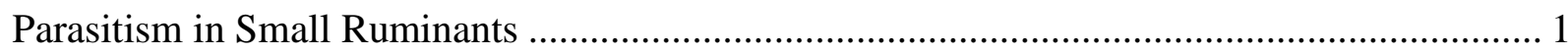

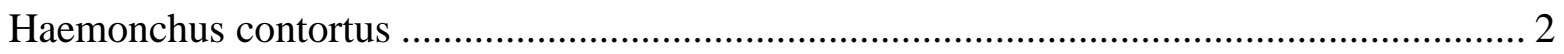

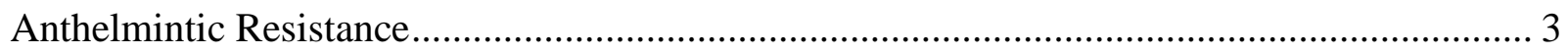

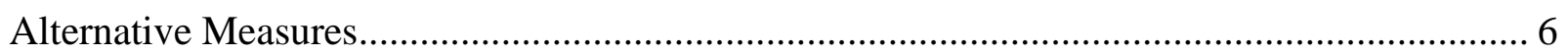

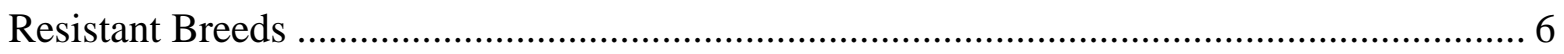

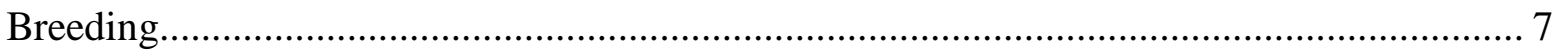

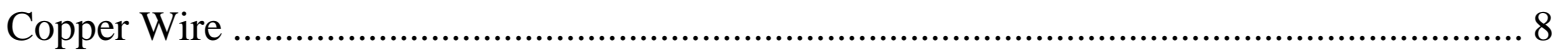

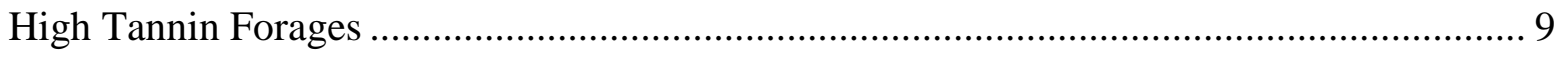

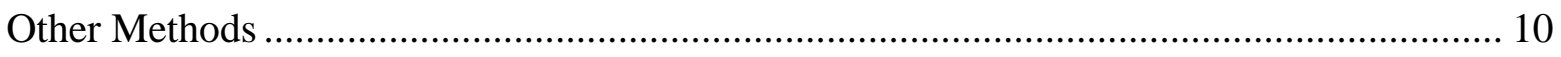

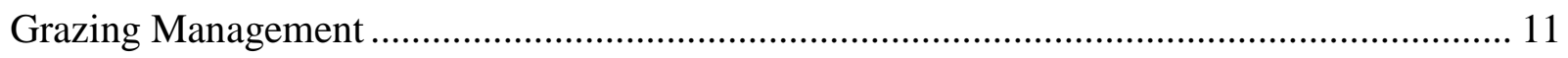

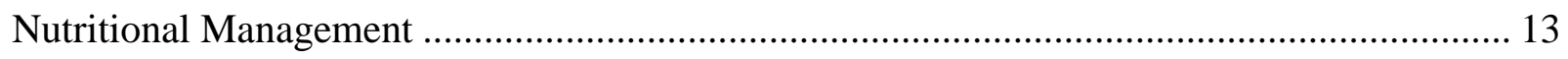

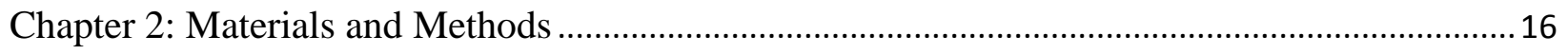

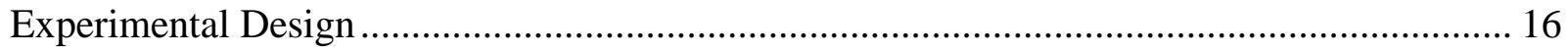

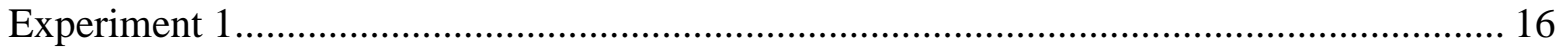

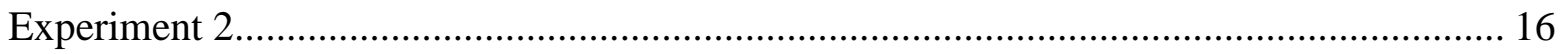

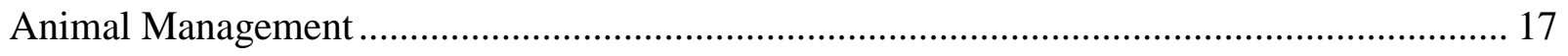

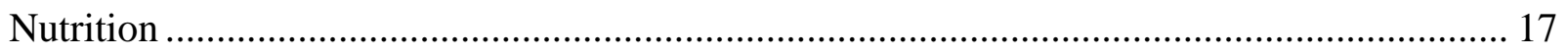

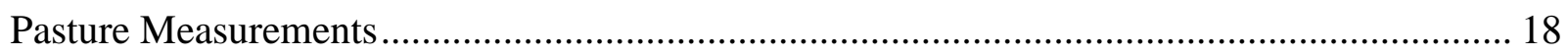

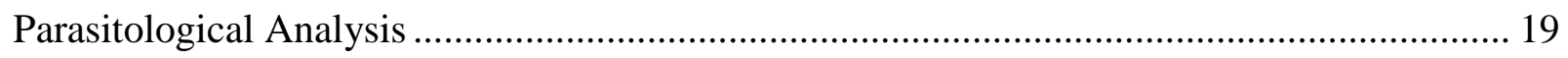

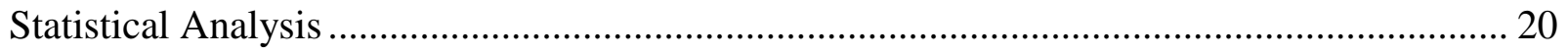

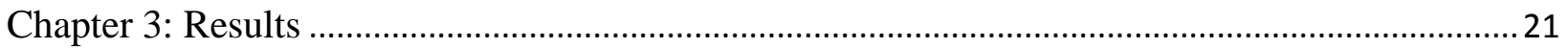




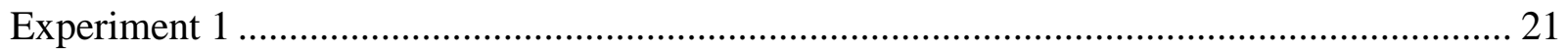

Parasitological Results......................................................................................... 21

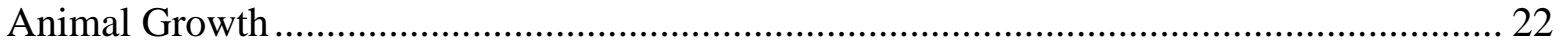

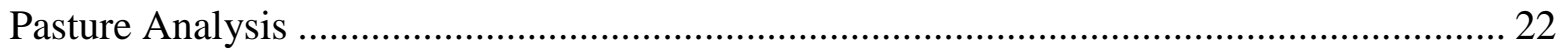

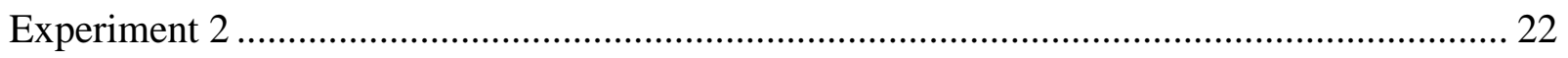

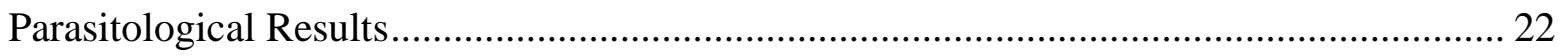

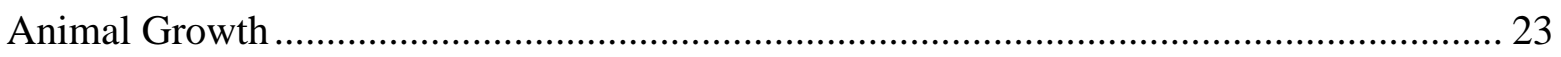

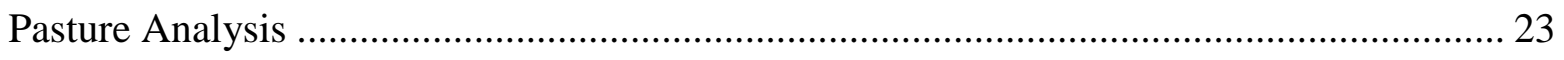

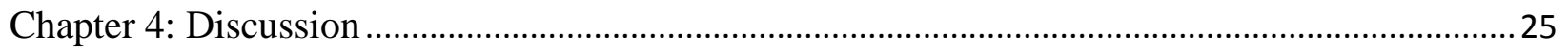

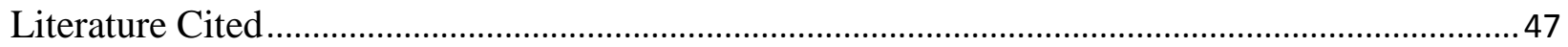




\section{Table of Figures}

Figure 1. Experiment 1 Fecal Egg Count during the experimental period. ........................ 29

Figure 2. Experiment 1 FAMACHA scores during the experimental period..................... 30

Figure 3. Experiment 1 Larval fecal culture speciation. ........................................... 31

Figure 4. Experiment 1 Gain and weights for transition and experimental periods........... 32

Figure 5. Experiment 1 Botanical Composition. ............................................................ 33

Figure 6. Experiment 2 FEC during the experimental period........................................ 34

Figure 7. Experiment 2 PCV during the experimental period. ........................................ 35

Figure 8. Experiment 2 Larval fecal culture speciation. ............................................ 36

Figure 9. Experiment 2 Total gain and weights across the experimental period................ 37

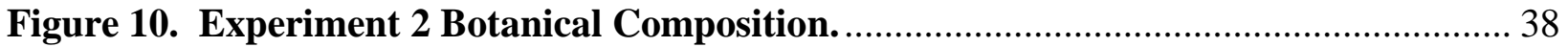




\section{List of Tables}

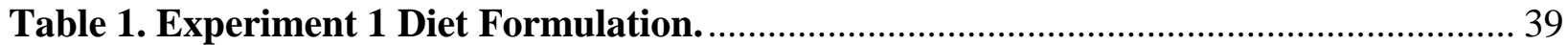

Table 2. Experiment 1 Chemical analysis of supplements. .............................................. 40

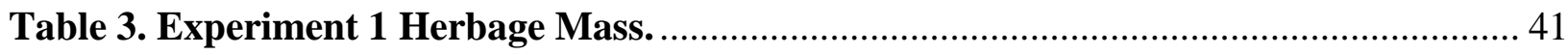

Table 4. Experiment 1 Pasture Analysis. ......................................................................... 42

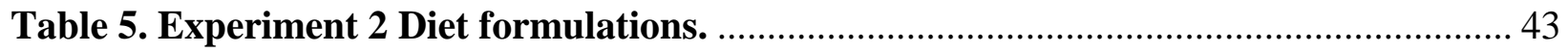

Table 6. Experiment 2 Chemical analysis of supplements. .......................................... 44

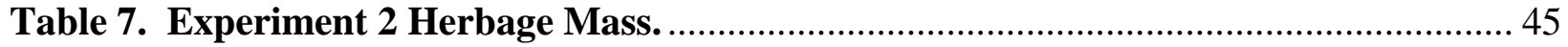

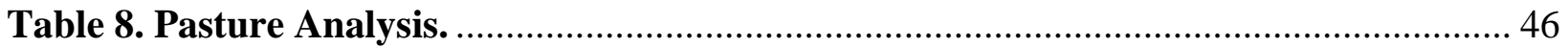




\section{Chapter 1: Gastrointestinal Nematodes in Sheep Parasitism in Small Ruminants}

Gastrointestinal trichostongylid parasites (GTP) are a common and widespread challenge to sheep production, as producers in the US reported stomach or intestinal worms on $74 \%$ of operations surveyed (USDA, 2001). Control of GTP can be costly with expenditures for anthelmintics estimated at $\$ 55 \mathrm{M}$ in Australia (Mcleod, 1995), while farmers were spending \$29.3M on anthelmintics in New Zealand (Vlassoff \& McKenna, 1994). Production losses were estimated at $\$ 141 \mathrm{M}$ (Mcleod, 1995) however this estimation was increased to $\$ 310 \mathrm{M}$ in 2005 (Sackett, 2005). Dramatic economic losses are caused by lack of gain, loss of body condition, reduced wool quality and death; all of which are symptoms of a GTP infection. Trichostrongylus colubriformus, Teladorsagia circuminta and Haemonchus contortus, all members of the Trichostrongylidea superfamily, are of greatest concern to producers. Teladorsagia and Haemonchus are both found in the abomasum whereas Trichostrongylus is found in the small intestine of small ruminants.

Trichostrongylus colubriformus is typically asymptomatic in sheep. When stress or large numbers of adult parasites are present, protracted diarrhea can occur (Bowman, 2003). This leads to weight loss and death. Trichostrongylus is a larger problem in countries with high production rates of sheep such as Australia and New Zealand but can and does exist in many other countries.

Teladorsagia circuminta tends to cause more problems for lambs than for older sheep, although, all animals grazing in temperate climate are likely infected. Teladorsagia can also cause diarrhea leading to weight loss and potentially death. However the major problem of this parasite is gastroenteritis (McNeilly et al., 2009). Once infected, larvae penetrate the abomasum gastric glands, where they mature and pass to the lumen. Teladorsagia disrupt host ability to 
convert pepsin to pepsinogen resulting in poorer digestion of feedstuffs compounding nutritional effects on the host.

\section{Haemonchus contortus}

The GTP of greatest concern for producers is Haemonchus contortus. Haemonchus is a blood feeding parasite that can be responsible for rapid death of grazing sheep of all classes. This GTP has a simple life cycle beginning with female worms producing eggs released in fecal matter onto pastures. Eggs develop in the environment, going through three larval stages and will reach the third larval or infective stage in one week under optimal conditions. Haemonchus larvae are sensitive to cool temperatures and desiccation, thus a warm, humid environment is needed for development. Infective stage larvae are consumed by grazing ruminants and travel with digesta to the abomasum and immediately begin feeding on blood, permitting further development to larval stage $4\left(\mathrm{~L}_{4}\right)$ and then finally develop into adults if the internal host environment is favorable (Bowman, 2003).

Larvae have the ability to become hypobiotic inside the host when conditions, outside the host are not optimal for larval development (Bowman, 2003). In the Northern Hemisphere this is most common during the winter months when temperature is too low for larval survival on pasture. Larvae in the host become dormant and metabolically inactive during this period. Adults and $\mathrm{L}_{4}$ can enter hypobiosis in the host, whereby adult worms remain in the abomasum while $\mathrm{L}_{4}$ larvae are undeveloped in the alimentary mucosa. This condition occurs until proper cues trigger their development or reactivation. Exact stimuli for this response are unknown; however, some cues may include photoperiod and hormone changes associated with parturition and lactation (Herd et al., 1983). This condition is typically associated with ewes and occurs after spring lambing resulting in GTP parasitism in young grazing lambs and is called "spring rise." While a 
"spring rise" can be observed in different classes of sheep, the periparturient rise (PPR) draws more attention. Courtney et al., (1985) hypothesized PPR to be caused by a relaxation in the immune system after partition, while others suggest an association with lactogenic hormones (Herd et al., 1983).

Severe pathophysiological damage can occur from the blood feeding of $H$. contortus. Studies have consistently shown high losses of plasma proteins and red blood cells (Bremner, 1969; Holmes \& Maclean, 1971; Dargie, 1975). Adult Haemonchus worms can consume 20\% of circulating erythrocytes in lambs and about 10\% circulating erythrocytes in adult sheep (Bowman 2003), leading to severe anemia, weight loss and hypoproteinemia. Reduced nitrogen retention has been linked to blood loss accounted for virtually all of the increased $\mathrm{N}$ flow to the duodenum in parasitized animals (Rowe et al., 1982). Anemia can be verified by low hematocrit and lack of plasma protein in the blood. On-farm diagnosis is done by color classifying the redness of periorbital membranes otherwise known as the FAMCAHA® system (Bath, 1996). Lack of redness indicates anemia that may be attributed to a Haemonchus infection. "Bottle jaw" is also a common sign of a heavy Haemonchus infection as the loss of plasma protein in blood manifests itself as submaxillary edema, or bottle jaw. Animals already suffering from stress, poor body condition, malnutrition or a heavy infection have a grave prognosis if left untreated. The pathogenic effects of Haemonchus leave the host incapable of compensating for blood loss resulting in death.

\section{Anthelmintic Resistance}

The first broad spectrum nematocide was released in 1961 (Kaplan, 2004). Demand for anthelmintic products was a global phenomenon. Three classic classes of anthelmintics exist that operate on different physiological functions of the nematode. Benzimidazoles, typically white 
dewormers, interfere with energy metabolism on a cellular level. Nicotinic agonists, including imidazothiazoles (IMID), cause spastic paralysis of worms and have a narrow margin of safety tetrahydropyrimidine (TETR), also in this class, mimics activity of acetylcholine which initiates muscular contractions leaving the parasite unable to feed resulting in starvation. The final class is macrolytic lactones which includes avermectins and milbemycins. Their mode of action interferes with GABA-mediated neurotransmission causing paralysis and death of the parasite (Martin, 1997). By the early 1980's reports of multiple drug resistant (MDR) nematodes began appearing worldwide (Kaplan, 2004). In 2008 a new class of anthelminitic was discovered (Kaminsky et al., 2008). The newest drug class amino-acetonitrile derivatives (AAD) includes monepantel. The mode of action of AADs induce hypercontraction of the parasites body wall muscles which lead to paralysis and ultimately death. Resistance appeared quickly in Trichostrongylus and Teladorsagia (Scott et al., 2013) and continued with Haemonchus.

Phenothiazine was used before broad spectrum anthelmintics. Resistance to this chemotherapeutic was first reported in the late 1950's (Drudge et al., 1957). First reports of resistance occurred soon after broad-spectrum anthelmintics were approved for use. Thiabendazole was introduced in 1961 and reports of resistance by Haemonchus were noted three years later (Drudge et al., 1964). This trend continued as new drugs and new classes of dewormers were released. By 2008, a study conducted in the southeastern United States on 46 sheep and goat farms found resistance or suspected resistance to benzimidazole on $98 \%$ of farms, $85 \%$ to levamizole and ivermectin as well as $30 \%$ to moxidectin. Haemonchus larvae resistant to all 3 drug classes were recovered from $48 \%$ of farms (Howell et al., 2008).

The four main factors that determine how fast resistance occurs include: 1) number of worms in refugia; 2) gene frequency for resistance in untreated populations; 3) resistance is 
dominant or recessive trait; and 4) biological fitness of resistant worms (Coles, 2005). Refugia is defined as the population of parasites not exposed to anthelmintics, such as larvae on pasture or those not yet affected by treatment. By increasing refugia the number of susceptible worms also increases. Frequent deworming programs reduce refugia, as worms exposed to a specific anthelmintic on a frequent basis can lead to mutations that facilitate resistance. Frequency of mutation within a population affects how rapidly a population may become resistant, thus a greater frequency of resistant alleles reduces length of anthelmintic efficacy. According to Le Jambre et al., (2000) genetic resistance to ivermectin in Haemonchus is completely dominant hastening the development of resistance. Fitness between resistant and susceptible worms is the last major factor affecting development rate of resistance. Worms must be fit enough to complete the life cycle and compete with susceptible worms while doing so.

The FAMACHA@ system was created to help identify animals with anemia known to be associated with Haemonchus infections. Periorbital mucosal membranes of small ruminants are observed visually and classified by color into 5 numerical categories associated with normal bright red, pink, through pale pink and white or devoid of color. Selective treatment of animals determined to be anemic based on FAMACHA score can greatly reduce the frequency of chemotherapeutic treatment. Doing so can help minimize development of resistant GTP populations by maintaining refugia in untreated animals. To maintain refugia, a method to select which animals are to be treated is required that is rapid and does not require fecal egg counts. The FAMACHA technique was created in South Africa (Bath, 1996) and has been tested with encouraging results. Sensitivity and specificity tests have been conducted in the United States to determine the validity under a range of climatic conditions. FAMACHA® scores were compared to PCV values for 847 and 537 sheep and goats, respectively, in the southeastern United States. 
FAMACHA scores of 4 and 5 and a PCV cut off at $15 \%$ led to sensitivity levels at $82.6 \%$ in sheep and $83.3 \%$ in goats. With the same criteria specificity levels were $89.1 \%$ and $70.9 \%$ in sheep and goats respectively (Kaplan et al., 2004). Therefore under conditions where Haemonchus is the dominant parasite FAMACHA is effective at identifying animals requiring treatment.

Using the FAMACHA technique in conjunction with other grazing and nutritional supplementation practices can help mitigate the influences of GTP on livestock health and performance. As much as $70-80 \%$ of GTP occurs in $20-30 \%$ of animals in a management group (Kaplan, 2004). Treating heavily infected animals only, as detected by FAMACHA techniques allows for a relatively rapid identification of severely infected animals. As anthelmintic resistance continues to develop, new approaches will be needed to manage the impact of Haemonchus infection. FAMACHA relies on an effective anthelmintic. If there is resistance to all available anthelmintics, then reducing exposure to GTP becomes critical.

\section{Alternative Measures}

\section{Resistant Breeds}

Sheep that are raised in tropical climates where Haemonchus thrives tend to be more resistant to infection. St. Croix, a hair type breed of sheep, has been found to be resistant to Haemonchus contortus infections (Courtney et al., 1985). In artificial primary infections of $H$. contortus, St. Croix lambs had a fecal egg count (FEC) 4 times lower than Dorset lambs and almost devoid during challenge infection. Similar results were obtained in a grazing trials with naturally acquired infections (Gamble \& Zajac, 1992). 
Although St. Croix exhibit the parasite resistant genetics producers are looking for, they lack basic performance characteristics needed in the United States. Hair sheep tend to be smallframed sheep that lack the muscle mass of most meat producing breeds. While these small carcasses may be good for ethnic or niche markets, purebred hair sheep cannot produce large enough size carcasses to meet demand of the US lamb market (Wildeus, 1997). Cross-breeding hair and wool sheep is an option to potentially keep parasite resistance while adding carcass merit. Black faced crossbred rams were bred to St. Croix ewes. Growth and carcass traits were measured. Daily gains in hair/wool crossbred were comparable to purebred St. Croix. Weight of cuts as a percentage of body weight were intermediate in hair/wool crossbreds as compared to black face crossbreds and St. Croix purebreds (Bunch et al., 2004). Without clear advantages in meat production, producers are hesitant to move forward with this cross. F1 progeny do not shed, and require shearing. The wool cannot be sold because the hair fibers have minimal value thus reducing overall profitability. However, breeding for resistance may be possible without incorporating hair sheep.

\section{Breeding}

Genetic selection for resistance is considered the ultimate tool in sustainable parasite control (Waller \& Thamsborg, 2004). By improving host genetic resistance, anthelmintic usage can be decreased, thereby reducing production costs and reducing potential of further development of drug-resistant GTP. Effects on performance, however, are less clear and vary based on environment (Bishop \& Morris, 2007). While resistance between breeds is very apparent, within-breed resistance should be focused on commercially-oriented breeds of sheep.

Within-breed heritability has been quantified using FEC. Woolaston and Piper (Woolaston \& Piper, 1996) showed that resistance was in fact heritable and FEC was reduced 
when Merino sheep were selected for resistance. When FEC was appropriately transformed it became a moderately heritable trait. By selecting animals based on differences in resistance, indirect selection for improved immunity is occurring (Hoste, 2011). However, greatest success in selection has come from New Zealand and Australia where there is one or two dominant breeds (Torres-Acosta 2008).

Studies to detect Quantitative Trait Loci (QTL) are currently at the forefront of withinbreed resistance. Identifying the specific QTL would allow for DNA tests to determine potential resistance to GTP infections. A study completed by Cockett (2005) found a QTL for PCV in the same location on chromosome 1 as the FEC QTL. While a number of QTL have been pinpointed this is still far from the hands of producer selection criteria.

On-farm selection for GTP resistance can be accomplished by retaining animals that were rarely treated with anthelmintic and culling those requiring more treatment; across a grazing season. Simple selection paired with additional methods of control are key to reducing the use of anthelmintics and reversing effects of anthelmintic resistance. Using natural methods to reduce parasite loads may also help to expose animals who struggle with high parasite loads and need to be culled from the herd.

\section{Copper Wire}

Copper oxide wire particles (COWP) are a recently developed control method for GIT. Copasure $^{\mathrm{TM}}$ boluses are commercially available containing either $2 \mathrm{~g}$ or $4 \mathrm{~g}$ COWP and are administered orally. These COWP remain in the abomasum for at least 32 days (Dewey, 1977) and COWP is released into the abomasum. This concentration of soluble copper creates a negative environment for the worms and they are expelled (Chartier et al., 2000). It should be 
noted that Chartier (2000) also determined that COWP was effective in controlling Haemonchus, an abomasal nematode, but not intestinal nematodes.

Soli et al., (2010) demonstrated that COWP could dramatically reduce FEC in a grazing study. After treatment with a $2 \mathrm{~g}$ bolus COWP, FEC was lower compared to untreated animals. Twelve days after treatment, sheep and goats had FEC reductions 94.3 and $74.9 \%$ respectively. For the remainder of this study, COWP treated sheep and goats had lower FEC than untreated groups. Adult worm burden was measured on day 28 in half the animals and worm burdens were reduced in COWP treated sheep by 67.2 and $85.8 \%$ in goats.

Sheep are very sensitive to copper thus accurate dosing is critical. Lambs given doses of $4 \mathrm{~g}$ or $6 \mathrm{~g}$ COWP had liver copper concentration (Burke et al., 2004) higher than the normal range of $25-500 \mathrm{mg} / \mathrm{kg}$ dry matter (Whitelaw et al., 1982). Lambs as young as 10 weeks did not show clinical signs given doses up to $5 \mathrm{~g}$ COWP (Bang et al., 1990). Similar results were found when ewes were given 10g COWP (Suttle, 1987). Therefore, before recommendations of COWP administration are given to producers, it is important to determine the copper intake of the flock. The risk of copper toxicity discourages producers and favors alternatives to GTP control.

\section{High Tannin Forages}

Condensed tannins (CT), found in some forages, can be used as a nutraceutical in the prevention and treatment of Haemonchus infections. Nutraceuticals have been defined as a food that provides medical or health benefits, while maintaining nutritive value (Kalra, 2003). Feeding plants containing CT, such as Sericea lespedeza, Quebracho (Shinopsis spp.) or birdsfoot trefoil (Lotus corniculatus), have been shown to reduce FEC (Marley et al., 2003; Paolini et al., 2003; Lange et al., 2006), thus reducing pasture contamination. 
Tannins create a tannin-protein complex as tannins bind proteins at a $\mathrm{pH}$ common to the rumen. This complex is dissociated in the abomasum at a lower $\mathrm{pH}$, thereby protecting protein from rumen degradation and permitting amino acid absorption to occur in the small intestine. By increasing the plane of nutrition, more nutrients are available to compensate for negative effects of parasite infection.

Tannin concentrations vary throughout forages species. The amount of tannin and their classification determines strength of the tannin-protein complex. When this complex becomes too strong hypoproteinemia can occur and is common when an overwhelming amount of tannins are being fed. Producers must be aware of the nutrient status of their animals when feeding tannins to avoid this. Feeding hay or pelleted feed may be a better option to ensure optimal amounts of CT (Lange et al., 2006).

\section{Other Methods}

There are many other methods that may have potential in the fight against Haemonchus. There are several species of micro fungi able to trap and destroy developing larval stages of GTP. Duddingtonia flagrans is known to survive the gastrointestinal tract of ruminant animals (Larsen et al., 1992). In feces, D. flagrans germinates and forms specialized structures that trap larvae. This fungus is effective at reducing larvae ingestion with results evident in both sheep (Pena et al., 2002) and goats (Terrill et al., 2004).

Australia has recently approved the use of a vaccine to control $H$. contortus. The vaccine contains a small dose $(5 \mu \mathrm{g})$ of native glycoproteins which have been isolated from intestinal cells of the parasite (Bassetto et al., 2014). Barbervax ${ }^{\mathrm{TM}}$ reduced FEC by $80 \%$ in the first year of use and $90 \%$ in the second on New England farms (About: Barbervax, 2014a). For maximum results Barbervax should be given 5 times over the grazing period. The first 3 injections should 
occur before large exposure to $H$. contortus (How to Use: Barbervax2014b). While Barbervax ${ }^{\mathrm{TM}}$ has the potential to greatly reduce the use of chemotherapeutics economic benefits should be reviewed. It is important to note this vaccine is not approved for use in every country.

New ideas are being developed every day to manage the growing worm problem in small ruminants, however, the answer may not be found in a single approach. Pairing different strategies to manage $H$. contortus infections may be the greatest defense. Grazing and nutritional management should be the basis of the integrated programs.

\section{Grazing Management}

Grazing management is extremely important from many aspects of livestock production. Not only does grazing provide food, it can affect health and well-being of the animals as well as profitability if done correctly. Grazing strategies can significantly impact amount of forage produced, forage quality and exposure to larvae. Many different strategies are available to limit exposure such as multi-species grazing, clean pastures, rotational grazing and stocking rate (Marley et al., 2006; Van Wyk, 2001; Burke et al., 2009; Hoste \& Torres-Acosta, 2011).

Different species of livestock exhibit different grazing habits. Animals graze on different portions of the sward and even different species of plants. Differential grazing behavior of livestock species can complement one another (Kumar et al., 2013). When grazing together, benefits can be observed in botanical composition and soil characteristics (Abaye et al., 1997). From a parasite standpoint, benefits of grazing different ruminant species in the same pasture result in GTP larvae being consumed by animals where they have limited survival. When cattle and sheep are grazed intermittently FEC are lower than when sheep and cattle and grazed together (Marley et al., 2006). While this grazing method works in the short term, long term problems may be even worse than the original. Ostertagia ostertagi and Trichostrongylus axei 
are reported to cause clinical disease and even death in sheep grazing cattle pastures (Abbott and McFarland 1991; O'Callaghan et al., 2008).

A practice that was once used heavily was "clean" pastures or drench and move theory. A pastures was saved for a grazing season so it could be considered free of larvae. Animals were dewormed and then placed on this pasture. To reduce contamination animals were placed on these "safe" pastures. Once resistance began, drench and move methods only escalated resistance (Van Wyk, 2001). By eliminating weak worms then moving to a fresh pasture resistant GTP have a perfect environment to thrive. This method was and continues to be common practice, amplifying the persistence of anthelmintic resistant GTP. Fortunately other grazing strategies such as rotational grazing and stocking rate are effective.

The most effective way to limit exposure to parasitic risk is to decrease the stocking rate (Hoste \& Torres-Acosta, 2011). Per surface unit, parasite infections increase with the square of animal load. Therefore, when animal density is doubled, parasite infestation quadruples (Kumar et al., 2013). Thamsborg et al., (1996) demonstrated this using 3 different stocking rates low, medium and high. High stocking rate animals had FEC 10 fold higher than medium and low stocking rates by the end of the second year (Thamsborg et al., 1996). Stocking rate affects autoinfection as, $H$. contortus becomes infective quickly, thus, reinfecting animals that have deposited eggs. Therefore, limiting time when grazing paddocks is critical to optimize rotational grazing. $H$. contortus can develop from an egg to $\mathrm{L}_{3}$ in $3-5$ days at $25-26^{\circ} \mathrm{C}$ but takes $15-30$ days $10-11^{\circ} \mathrm{C}$ (Rose, 1963). Season determines the safe grazing period, or rotational length, to prevent autoinfection.

Katahdin lambs were used to compare continuous and rotational grazing on worm burdens in Arkansas. Rotational grazed lambs were moved every 3.5 days and returned to the 
original plot after a 35 days. These lambs required less anthelmintic treatment however had a greater worm burden in their abomasum (Burke et al., 2009). A similar study was conducted in Australia using merino sheep to determine effects of rotational grazing in cool environments on GTP control. Three rotational methods were used including a high stocking rate (HI) which had relatively long grazing periods, a typical management system (TYP) and an intensive rotational (IR) system (Wallace et al., 1995) with short grazing periods and long rest periods. Animals grazed in the IR treatment had significantly lower FEC, were dewormed half as much, had a lower proportion of $H$. contortus and a higher hematocrit than those on the other two management systems (Colvin et al., 2008)

While grazing method is important to control potential infection, quality of the forage is also critical. Level of nutrition can affect resistance and resilience to parasite infections (Coop \& Kyriazakis, 1999). Rotational grazing with long rest periods has potential to reduce the quality of the forage. Therefore, balance must be made between forage quality and long rest periods, as nutrition should be the basis of parasite management programs.

\section{Nutritional Management}

Haemonchus contortus has the ability to cause severe anemia and hypoproteinemia due to blood feeding. Nutrition may be considered the most important factor in fighting parasite infections and can directly affect resistance and resilience (Torres-Acosta et al., 2012). Acquisition of immunity in young animals can also be influenced by nutrition (Coop \& Holmes, 1996). More specifically, interactions between the host and nutrition during parasite infections can be placed into two categories: 1) the influence of nutrient availability on host ability to mount a response against the infection and 2) the effects of nutrition on metabolic and pathophysiology disturbances induced by parasitism (Coop \& Kyriazakis, 1999). 
Inflammation and activation of acute phase responses to infection occur locally and systemically as a result of and damage caused by GTP (Colditz, 2003). These responses can place a significant burden on host nutritional resources. Nutritional resources are often partitioned into other bodily processes such as mucus production. Mucus is resistant to digestion and resorption from the small intestine so once it is formed its component amino acids are effectively unavailable (Lindsay et al., 1980). Production of immunological mediators such as; leukotrienes (MacRae, 1993) and cytokines (Grimble, 2002) require specific amino acids which may reduce their availability for other processes. Competition for nutrients exists in growing animals between the requirement to mount an immune response and the high metabolisable protein requirement relative to energy demand required for growth. This partitioning of nutrients between growth and immune response may explain lack of immune response in young animals (Coop \& Holmes, 1996). The addition of "protected" protein may increase availability of amino acids in the small intestine and possibly enable young lambs to mount more effective immune responses, while maintaining growth.

GTP reduce nutrient availability by reductions in feed intake and efficiency of absorbed nutrients. The relative impact of these two mechanisms depend upon the species on its location in the GI tract. Osteragia cicumcincta (abomasal) infections in growing lambs have shown to reduce voluntary feed intake (Sykes \& Coop, 1977) while T. columbriformis (intestinal) have shown a reduction in feed efficiency (Sykes \& Coop, 1976). Cytokine cascades associated with immune response to infections may also be a major factor inducing anorexia (Farthing \& Ballinger, 2001). Detailed experiments to examine underlying mechanisms have shown a key feature in host dysfunction to be increased endogenous loss of protein into the GI tract, due to plasma protein leakage and gut epithelial cells exfoliation (Poppi et al., 1986; Bown et al., 1991). 
As a result, protein synthesis in parasitized ruminants is diverted away from production processes to responses essential for maintenance of homeostasis such as plasma and blood protein synthesis, mucus production, repair of the GI tract mucosal integrity and maintenance of host defenses causing loses (Jones \& Symons, 1982; Symons, 1985; MacRae, 1993). Protein metabolism is more disturbed under parasitism than other components of the diet (Brown et al., 1991) suggesting that parasitized sheep need to synthesize an additional $50 \mathrm{~g}$ of protein per day.

Many studies have shown that protein supplementation may benefit animals from an immunological, parasitological, and production standpoint. Worm burden data from van Houtert et al. (1995) from 3 month old merino lambs killed at 35, 70, 105 and 140 days demonstrated that higher level of "protected" protein supplementation (50 or $100 \mathrm{~g}$ fishmeal /day) caused quicker expulsion of worms. Later in the experiment expulsion rate correlated with the concentration of eosinophils in the peripheral blood. Lambs fed isocaloric diets at differing proteins levels exhibited lower FEC at higher protein levels (Wallace et al., 1995). The number of recovered female worms did not differ however worms from the higher protein level were shorter and carried less eggs, meaning lambs were better able to control worm fecundity. Lambs on the higher protein diet also produced higher levels of parasite-specific $\operatorname{IgA}$ and there was a significant association between increased $\operatorname{IgA}$ activity against parasite larvae and reduced adult worm length (Strain \& Stear, 2001). Similarly, growing lambs fed iso-energetic diets that were of varying protein levels had lower FEC and higher growth rates when the CP level was higher (19 or $22 \%$ versus 10 or $13 \%$ ) (Datta et al., 1999). Nutritional management paired with a grazing plan can be a large component of integrated parasite-control programs.

The National Research Council recommends an intake of $155 \mathrm{~g} / \mathrm{d}$ of $\mathrm{CP}$ in lambs weighing $20 \mathrm{~kg}$ to gain $300 \mathrm{~g}$ per day. On pasture supplementation is needed in order to reach this. 
Thus, the objective of this research project was to determine the best source of protein supplementation for grazing lambs to overcome negative effects of parasite infection while maintaining growth.

\section{Chapter 2: Materials and Methods}

\section{Experimental Design}

\section{Experiment 1}

This experiment was conducted August through October 2013 at the West Virginia University Organic Research Farm in Morgantown, West Virginia. Spring-born Suffolk crossbred lambs were stratified by adjusted $90 \mathrm{~d}$ weaning weight and randomly assigned to one of three supplementation groups. Group $1(\mathrm{n}=13)$ received alfalfa pellets (AFP) (15\% CP), group $2(n=15)$ received a corn and soybean meal mixture (CSM) (19\% CP) and group $3(n=14)$ received a corn, soybean meal and fish meal mixture (CFM) (19\% CP). Protein supplementation equated to $1.28 \%$ of average group body weight (BW) in ALF group to compensate for lower CP and $1 \%$ for CSM and CFM for an iso-nitrogenous supplementation. Four weeks (0-4) immediately following weaning were considered a transition period and the following four weeks (4-10) was the experimental period. Lambs were weighed, FAMACHA scored and fecal sampled every two weeks during both transition and experimental periods. Average daily gain (ADG) was calculated for transition and experimental periods separately. Total gain (TG) was calculated as a function of initial experimental weight subtracted from ending weight.

\section{Experiment 2}

This experiment was conducted at the West Virginia University Animal Research Farm in Morgantown, West Virginia from June to August 2014. January-born purebred Suffolk and 
Dorset $\mathrm{x}$ Texel crossbred lambs weaned at 60 days were stratified by weight and randomly assigned to one of three supplementation groups each with two pasture replications ( $\mathrm{n}=8 /$ group). Group $1(n=16)$ received $(C S M)$, Group $2(n=16)$ received (CFM) and group $3(n=16)$ received a corn, soybean meal and fish oil mixture (CFO) (19\% CP). Lambs were iso-nitrogenously supplemented at $1 \%$ of average group body weight (BW). During a four week transition period, the lambs were housed in an elevated floor barn and slowly adjusted onto new diets and weighed weekly. During week 2 and 3 of the transition period lambs were orally drenched with $2000 \mathrm{H}$. contortus $\mathrm{L}_{3}$ larva. After this period lambs were put onto pasture for the remaining 12 weeks and randomly assigned to pasture replicated within group. Lambs were weighed, FAMACHA scored and fecal sampled every two weeks. Blood was also collected for packed cell volume (PCV) at each sampling date. Average daily gain (ADG) was calculated for the experimental period while TG was calculated as previously described.

\section{Animal Management}

Supplemental grain was fed to lambs twice daily, morning and afternoon in equal proportions. Lambs had unlimited access to Nature's Best Sheep Mineral (Kreamer Feed Inc.). Lambs were grazed in small plots on predominantly fescue pastures with a maximum grazing period of three days. Plots had a minimum of a 56 day rest period before grazing again. Each plot housed a temporary shelter for shade and rain protection. All lambs were moved on the same day. If lambs had 2 consecutive FAMACHA score of 5 they were dewormed with moxidectin (Cydectin) at $0.2 \mathrm{mg} / \mathrm{kg}$.

\section{Nutrition}

For experiment 1 alfalfa pellets were purchased from Countryside Organics. CSM and CFM supplements were formulated to be iso-nitrogenous and were hand mixed in 50 pound 
batches, weekly. Organic cracked corn and soybean meal were purchased from Kreamer Feed Inc. and fish meal was purchased from Countryside Organics (TerraMar Ingredients L.L.C.). During experiment 2 all supplements were formulated to be iso-nitrogenous and iso-caloric. Diets were mixed in 300 pound batches using a Davis Precision Horizontal Batch Mixer (H. C. Davis Sons MFG. Co., Inc, Bonner Springs, Kansas) approximately every 3 weeks. Organic soybean meal was purchased from Kreamer Feed Inc. and cracked corn and fish meal were purchased from Countryside Organics (TerraMar Ingredients L.L.C.). Conventional soybean meal was purchased from Cargill (Wayzata, MN). Fish oil was donated by Organic Technologies (Coshocton, OH). Samples were taken from every batch. At the end of both studies, samples from within each supplement were thoroughly mixed together and one final sample was analyzed for composition at the WVU Rumen Profiling Lab. All nutritive analysis described will be performed in duplicate. Dry matter $\left(105^{\circ} \mathrm{C}\right)$, ash and $\mathrm{CP}($ Kjeldahl $\mathrm{N} \times 6.25)$ were determined according to AOAC (2002). Neutral detergent fiber (NDF), acid detergent fiber (ADF) were determined sequentially according to Van Soest et al. (1991) using modifications outlined in the Ankom Fiber Analysis procedure.

\section{Pasture Measurements}

Permanent grazing lands used in these experiments were mixed swards of tall fescue (Schedonorus phoniex (Scop.) Holub.), orchardgrass (Dactylis glomerata L.), Kentucky bluegrass (Poa pratensis L.) and other cool season grasses; legumes predominantly red clover (Trifolium pretense L.) and white clover (T. repens L.), with some forbs. Forage biomass was estimated by at least 20 sward heights taken on transects regularly spaced across each plot. These measurements were taken before and after grazing. Sward height was converted to herbage mass using the following equation: herbage mass $(\mathrm{kg} \cdot \mathrm{ha}-1)=266.15 *$ sward height $(\mathrm{cm})+265$. This 
equation was obtained by site specific calibration, using 10 paired samples collected monthly from August to November in each unit, between 2004 and 2009. Six samples were clipped pregrazing at two week intervals on the same transects used for forage biomass estimation in each plot to determine botanical and nutritional composition of the herbage being grazed. In experiment 2, samples were also taken after grazing to determine intake. Samples were placed in paper bags and stored at $0^{\circ} \mathrm{C}$ until sorted and dried. Samples were hand sorted into grass, forbs, legumes and dead vegetation. Sorted samples were oven dried for 48 hours at $60^{\circ} \mathrm{C}$. Following weighing they were reconstituted, ground and analyzed for nutritional components. Forage quality was determined by chemical analysis of samples collected. When processed, samples were dried at $60^{\circ} \mathrm{C}$ in a forced-draft oven for 48 hours, weighed and ground to 1-mm particle size through a Wiley mill (Model 4: Arthur H. Thomas Co., Philadelphia, PA). All nutritive analysis were performed as previously described.

\section{Parasitological Analysis}

For fecal egg quantification, 4 grams of feces was collected from each lamb and added to $56 \mathrm{ml}$ of saturated salt solution (SPG 1.20). The mixture was filtered over a double layer of cheesecloth. Eggs of major parasite genera were counted using a McMaster counting chamber (Chalex Corporation. Wallowa, OR) at 100x magnification. Total count was multiplied by 50 to determine eggs/g of feces (Whitlock, 1948). Excess feces was saved every other collection to determine Trichostrongylid species present. Excess feces were mixed with sterile peat moss and activated charcoal and incubated for one week at $30^{\circ} \mathrm{C}$ to allow eggs to develop to $\mathrm{L}_{3}$ stage. Larvae were collected using the Baerrman Technique (Zajac and Conboy, 2012) and 100 larvae were selected and sheaths were measured to determine species. 


\section{Statistical Analysis}

Data were analyzed using the MIXED procedure of SAS using the fixed effects of treatment and period and two-way interactions. Data reported are least squared means and associated standard error of the LS mean. Fecal egg count data were log transformed using the formula $\log _{10}(\mathrm{FEC}+25)$ and back transformed for means reporting. Significance was accepted at $P<0.05$. 


\section{Chapter 3: Results}

\section{Experiment 1}

Parasitological Results

During the experimental period, CFM (2280 eggs per gram) (epg) had the greatest reduction of FEC over the 42 day experimental period although AFP (1587 epg) and CSM (1247 epg) also dropped. At day 42 CSM (1826 \pm 526 epg) had a FEC nearly double CFM (808 \pm 158 epg) and triple AFP $(613 \pm 167 \mathrm{epg})$. However, there was no significant treatment by date interaction in FEC (Figure 1A). When FEC was averaged over the course of the experiment AFP $(1279 \pm 203 \mathrm{epg})$ and CFM $(1519 \pm 359 \mathrm{epg})$ were significantly $(P \leq 0.06)$ lower than FEC associated with CSM $(2495 \pm 518)$ (Figure 1B).

Over the course of the experimental period, FAMCHA@ scores were relatively consistent for CSM resulting in no change from day 0 to 42. FAMACHA scores of CFM decreased suggesting an improvement in animal anemia status from day 0 to 42 . While the treatment averages and treatment by time interaction were not statistically significant (Figure 2A), the reduction in scores becomes biologically relevant. On average, AFP reduced FAMCHA by 0.6 of a score while CFM doubled reduction with a 1.3 score change (Figure 2B) from day 0 to 42 .

Worm speciation was conducted on 28 day intervals and was pooled across treatment groups. In the transition period at day -14 Haemonchus represented $44 \%$ of the worms present in fecal cultures (Figure 3A). As the temperature decreased, Haemonchus concentration decreased as well. Day 14 and 42 had only $23 \%$ and $24 \%$ of Haemonchus present, respectively, relative to that in samples collected earlier in the season (Figures 3B \& 3C). 
Animal Growth

The supplements CSM and CFM were formulated to be iso-nitrogenous while AFP was purchased as a complete feed and contained $4 \%$ less CP (Table $1 \&$ Table 2). Animals receiving CSM and CFM supplement lost weight during the transition period from day -28 to day 0 (Figure 4C). During this same time, AFP supplemented animals gained weight $(0.008 \pm 0.02 \mathrm{~kg} / \mathrm{d})$, and doing so more significantly $(P<0.03)$ than CSM $(-0.06 \pm 0.2 \mathrm{~kg} / \mathrm{d})$ and CFM $(-0.07 \pm 0.02 \mathrm{~kg} / \mathrm{d})$ (Figure 4A). Despite losing the most weight CFM $(7.54 \pm 0.67 \mathrm{~kg})$ had the highest total gain from day 0 being significantly $(P=0.01)$ higher than AFP $(4.26 \pm 0.90 \mathrm{~kg}$, with CSM $(5.72 \pm$ 0.71) being intermediate (Figure 4B).

Pasture Analysis

Herbage mass offered to each treatment was relatively similar for the entire experiment (Table 3). Disappearance tended to be numerically higher when herbage mass was also higher. This can be attributed to trampling of the taller grass. On average, between treatments disappearance was similar (Table 3). Grass concentration was also consistent between groups ranging from $75-90 \%$ (Figure 5). Legume concentration varied from $0-12 \%$ being the highest at day 38 for AFP (Figure 5). This higher concentration of legumes impacted CP increasing AFP 8 $\%$ higher than CFM and $10 \%$ higher than CSM (Table 4). Forage quality was similar for the rest of the experiment, therefore not effecting protein intake of lambs.

\section{Experiment 2}

Parasitological Results

Over the course of the experiment no treatment by time interaction was observed for FEC (Figure 6A). Animals receiving either the CSM or CFO supplement had FEC that continued to increase during the experiment, while that of animals receiving CFM was relatively consistent 
between days 28 and 70. When FEC was averaged over the course of the experiment, lambs receiving CFM had significantly lower $(P<0.05)(831 \pm 102$ epg $)$ FEC than lambs supplemented with CSM $(1074 \pm 111 \mathrm{epg})$ and tended $(P=0.1564)$ to be lower than CFO supplemented animals (1015 $\pm 95 \mathrm{epg})$ (Figure 6B).

There was no treatment by time interaction for PCV (Figure 7A). Averaged across all time points, lambs supplemented with CFO $(31.22 \% \pm 0.39)$ had significantly $(P<0.05)$ higher PCV than either CSM $(29.57 \% \pm 0.39)$ or CFM $(29.05 \% \pm 0.39)$ supplemented lambs (Figure 7B). Numerically, the CFM supplemented lambs had the lowest PCV until day 56 while CFO had the highest during the entire experimental period.

Worm speciation was determined at the beginning of each month. Due to the trickle infection during the transition period, more than $99 \%$ of the larvae present in the fecal culture in June were Haemonchus (Figure 8A). Lambs ingested larvae present on pasture in July, August and September; however, Haemonchus remained the predominant species at $60 \%$ or greater throughout the experimental period (Figures 8B-D).

Animal Growth

In experiment 2, all supplements were formulated to be iso-caloric and iso-nitrogenous (Table 5 \& Table 6) to facilitate comparable lamb performance among treatments (Figure 9A). Live weights decreased between day 0 and 14 . Growth was suppressed until day 42 where it began it increase and plateau again (Figure 9B).

Pasture Analysis

Herbage mass offered to each treatment was relatively similar for the entire experiment (Table 7). Disappearance tended to be numerically higher when herbage mass was also higher. This can be attributed to trampling of the taller grass. On average, between treatments disappearance was 
similar (Table 7). Grass concentration was also consistent between groups ranging from 75-85\% (Figure 10). Legume concentration varied from 3-18\% being the highest at in August for CFM (Figure 10). While the botanical composition varied quality of the grass was relatively similar between treatments across the experimental period, therefore not effecting protein intake of the lambs (Table 8). 


\section{Chapter 4: Discussion}

These results show that protein supplementation to lambs on pasture has the potential to reduce FEC and promote growth despite having a GTP infection. Reduction of FEC and improved anemia indicators demonstrate that lambs were better able to overcome natural and controlled infections. In experiment one, addition of by-pass protein had net positive effects on growth, consistent with studies evaluating the effects of feeding ruminants bypass protein (van Houtert et al., 1995; Beermann et al., 1986). Lambs supplemented with AFP did not lose weight during the transition period, presumably resulting from reduced diet change, yet failed to gain as well as CFM during the experimental period. Supplementation of CFM resulted in greater lamb growth after transition indicating bypass protein may contribute to the increased growth.

Soybean meal, a source of mostly degradable protein, has been shown to increase growth of animals with an infection (Wallace et al., 1996). Similarly, van Houtert et al., (1995) recorded more growth when feeding increasing levels of fishmeal. Infected lambs receiving the highest concentration of fishmeal outgained uninfected lambs without any fishmeal supplementation. Contrary to the results presented in this thesis the addition of by-pass protein did not yield the same results for parasitological parameters in the van Hourtert et al., (1995) study. FEC remained similar until day 112 when the high fishmeal group began to drop. Unlike these results FEC dropped much quicker in experiment 1 at day 14 and day 28 in experiment 2 . Change in FAMACHA could be associated with the FEC reduction as it is an indicator of anemia. FEC was decreased for animals supplemented with a diet that included fish meal. FAMACHA was also changed over a full score. Coop et al., (1995) demonstrated that FEC could be decreased with post ruminal infusion of bypass protein while Wallace et al., (1995) showed no difference in FEC when soybean meal was used a protein source. 
While reduction in FEC is an important factor when choosing a supplement, maximizing growth is critical. The fish meal diet not only contained a higher concentration of by-pass protein but also more oil. While different sources of oil have been shown to reduce FEC (Squires et al., 2010) others have shown no effect (Ketzis et al., 2002). In experiment two CFO supplemented lambs had a FEC intermediate to CSM and CFM, indicating that oil alone was not responsible for the FEC reduction. Although previously seen, PCV was significantly higher for CFO supplemented animals, it may not be biologically relevant as CFO was only 2 percentage points higher than CFM and 1.5 percentage points higher than CSM. Growth was not impacted by supplement groups in experiment two. All diets were formulated to be iso-nitrogenous and isocaloric leaving little room for growth differences. Lambs were approximately 6 months old when placed on pasture and reaching the peak of their growth curve. Grazing animals have been shown to undergo a "summer slump" in growth due to a decrease in pasture availability and quality (Abaye et al., 1994). Grass quality decreases in June and July lowering the nutritional plane of the animals which is demonstrated by chemical analysis of pasture.

Pasture data from experiment one shows that the loss of BW during the transition period could be associated with lower pasture quality. On day 14, CP almost doubled from day 0 throughout all treatment groups. This increase in pasture quality could have contributed to the larger gain in the experimental period. Although pasture quality was improved, botanical composition did not change. Forage mass offered was similar across all three treatments throughout the experiment. Disappearance was similar showing that intake should not have affected growth. Similar results were seen in experiment two. The fields used in this study had a much higher percentage of legumes, being present in all treatment groups throughout the length of the experiment and less dead material. Intake was once again not a factor in the growth of 
lambs. Similar amounts of forage were offered throughout the experiment and disappearance remained similar as well.

The data presented in this thesis suggest that when paired with an intensive grazing management strategy, bypass protein supplementation has the ability to reduce FEC and increase growth. Although positive results were seen from all four diets fish meal containing diets demonstrated the most benefits from year to year with increased growth and the largest FEC reduction. This parasite control approach can be easily applied to producers today, however some changes should be made. In order for producers to receive maximum benefit from this type of program future studies need to be done using other types of grazing management that are less labor intensive. Although growth may be maximized labor cost may outweigh the benefits of increased growth. Knowing the quality of the forage is also critical when implementing a supplementation program. When forage quality is low the amount of supplementation needed may be higher in order for the animal to reach the recommended protein intake of $155 \mathrm{~g} / \mathrm{d} \mathrm{CP}$ to gain $0.3 \mathrm{~kg} / \mathrm{day}$ (National Research Council). Secondary effects of feeding fishmeal should also be explored. It is important to know the impacts on meat quality and consumer perception of the meat that fishmeal may have.

There is no silver bullet for the control of GTP however integrated management systems have proved to help overcome the negative effects. While it is important to consider all techniques such as breed selection, selective deworming and pasture management the most important factor should be nutrition. Nutrition may be considered the most important factor in fighting parasite infections and can directly affect resistance and resilience (Torres-Acosta et al., 2012). By implementing the use of bypass protein supplementation the negative effects of GTP, specifically $H$. contortus can be overcome. 

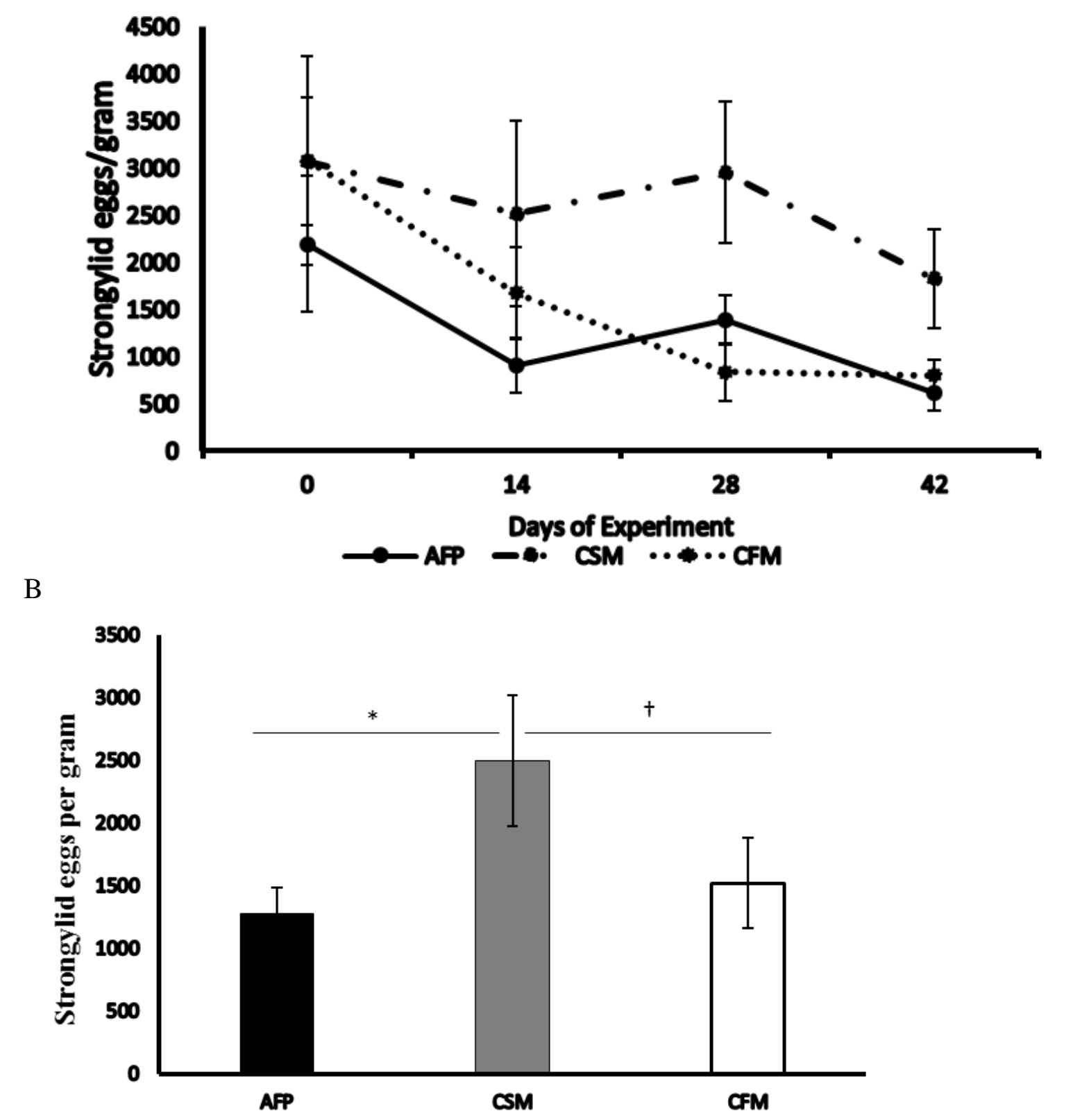

Figure 1. Experiment 1 Fecal Egg Count during the experimental period. Biweekly fecal egg count (FEC) of alfalfa pellets (AFP), corn and soybean meal (CSM) and corn, soybean and fishmeal (CFM) during the experimental period (A). Average FEC for AFP, CSM and CFM during the experimental period (B). Error bars represent SEM. * represents significance at $P=0.03$. $\dagger$ represents significance at $P=0.059$ 
A
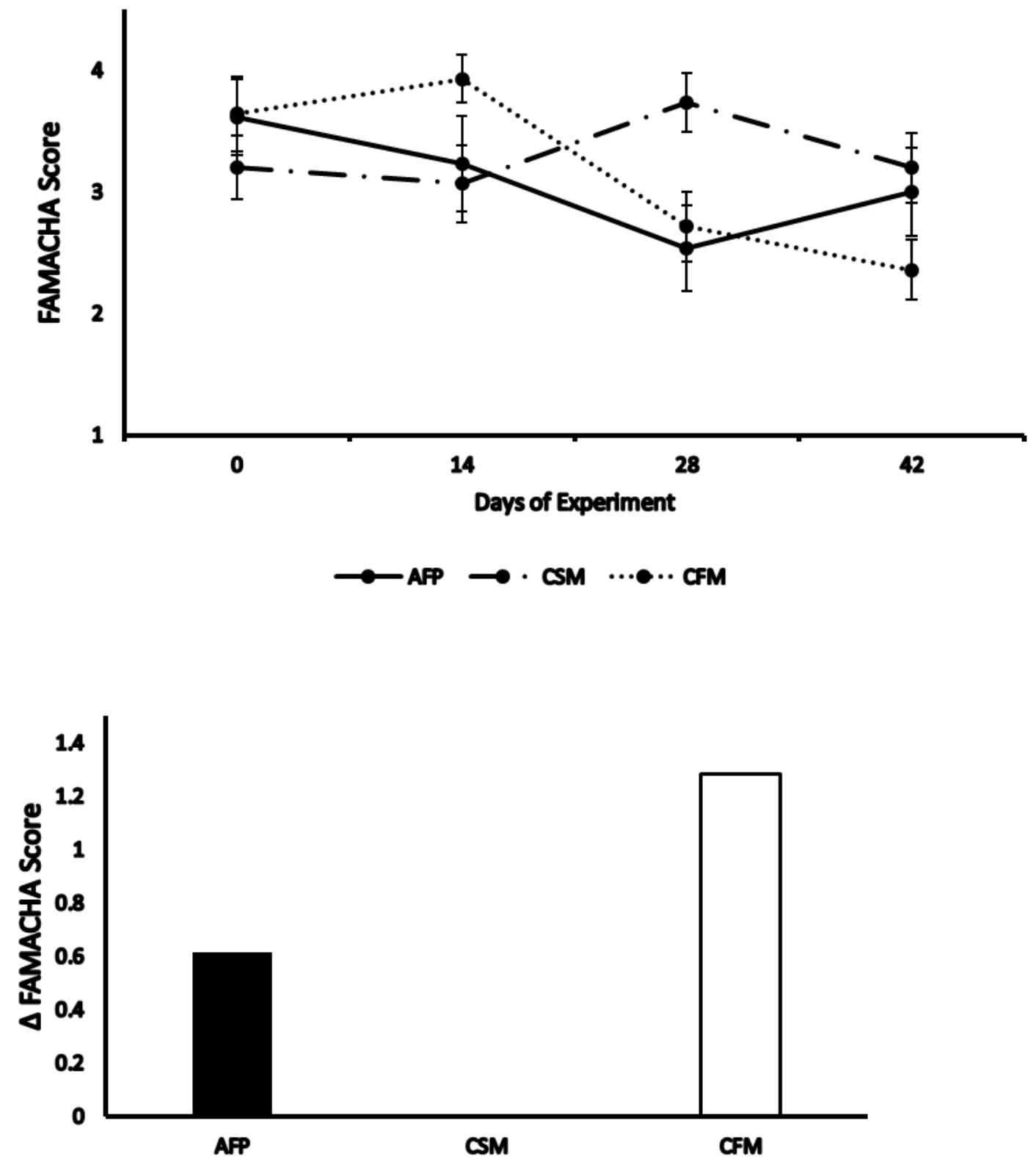

Figure 2. Experiment 1 FAMACHA scores during the experimental period. Biweekly FAMACHA scores for alfalfa pellet (AFP), corn and soybean meal (CSM) and corn, soybean and fishmeal (CFO) during the experimental period (A). Average negative change in FAMACHA from day 0 to day 42 for AFP, CSM and CFO (B). Error bars represent SEM. 
A

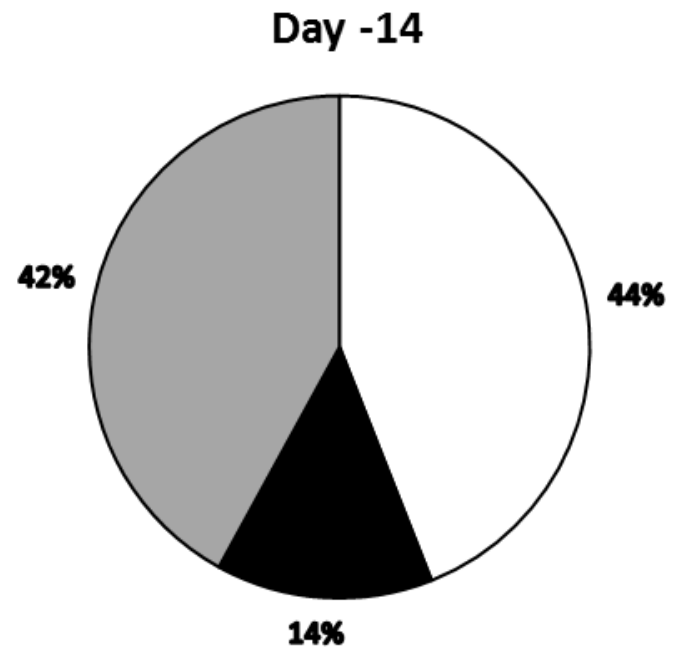

C

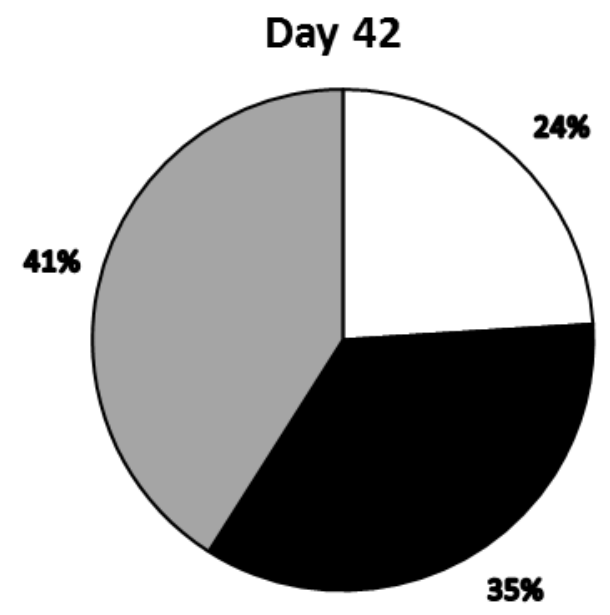

B

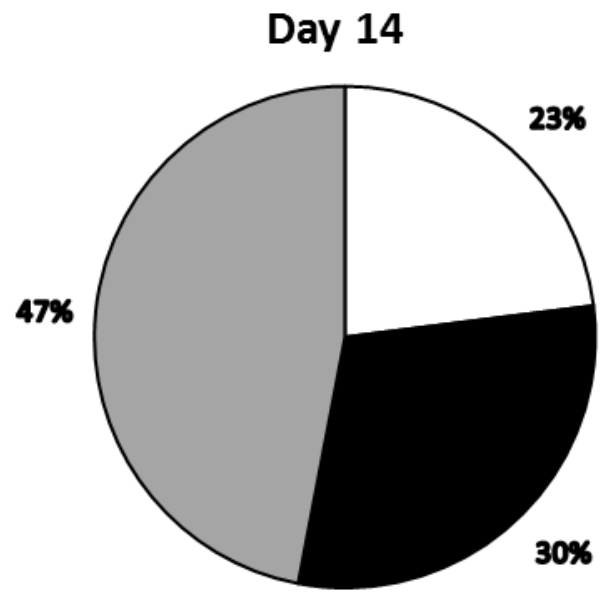

口Haemonchus

- Telodorsagla

口Trichostrongylus

Figure 3. Experiment 1 Larval fecal culture speciation. Feces was collected from each treatment was pooled together to determine larval speciation. A. Day -14. B. Day 14. C. Day 42. 
A

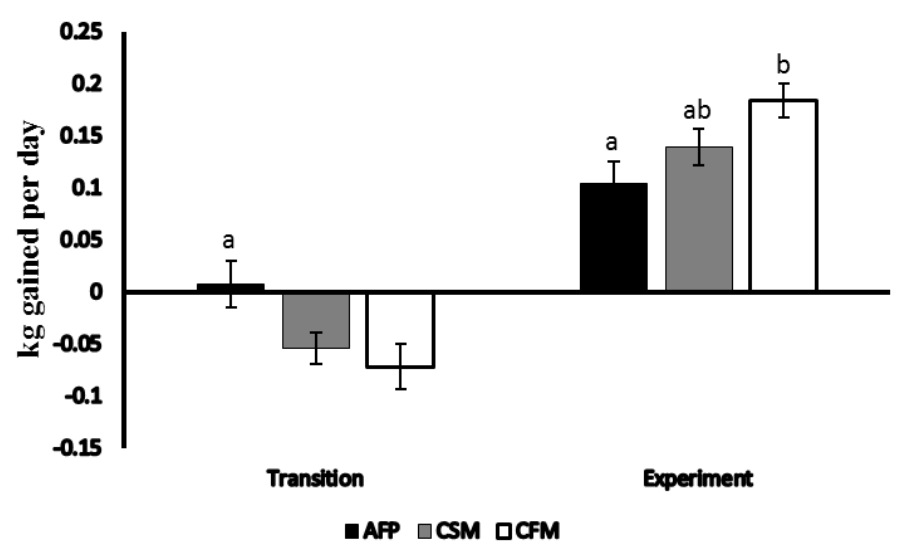

$\mathrm{C}$

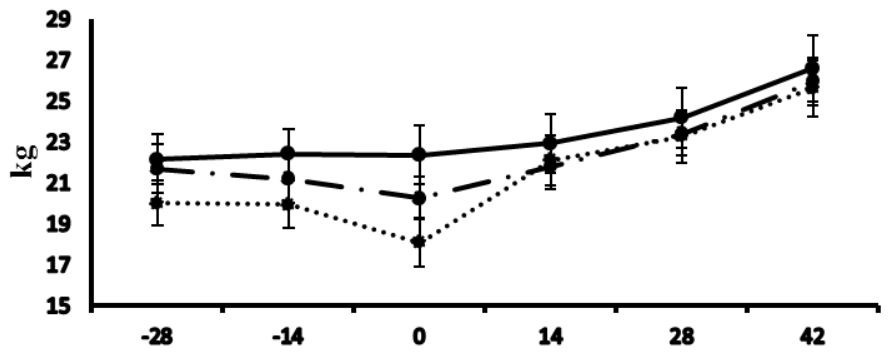

Figure 4. Experiment 1 Gain and weights for transition and experimental periods. Average daily gain across the transition and experimental period for alfalfa pellets (AFP), corn and soybean meal (CSM) and corn, soybean and fishmeal (CFO) (A). Average total gain during the experimental period for AFP, CSM and CFO (B). Biweekly weights for CSM, CFM and CFO (C). Different letters represent significance at $P<0.05$. Error bars represent SEM. Analysis were done within period.
B

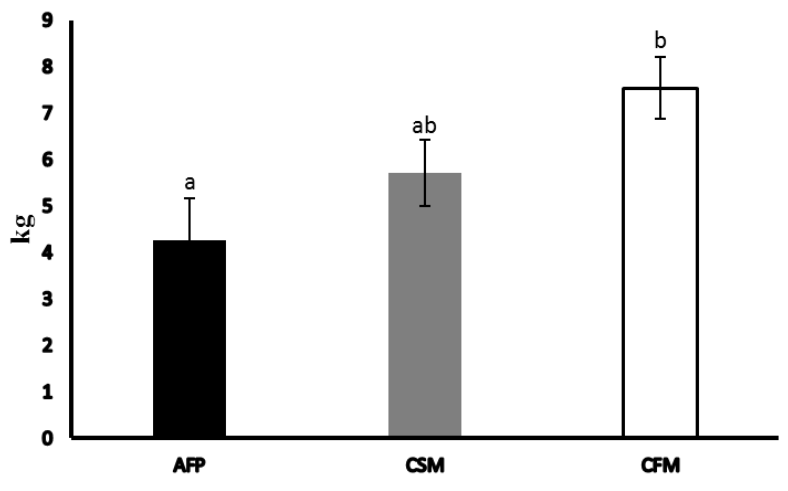




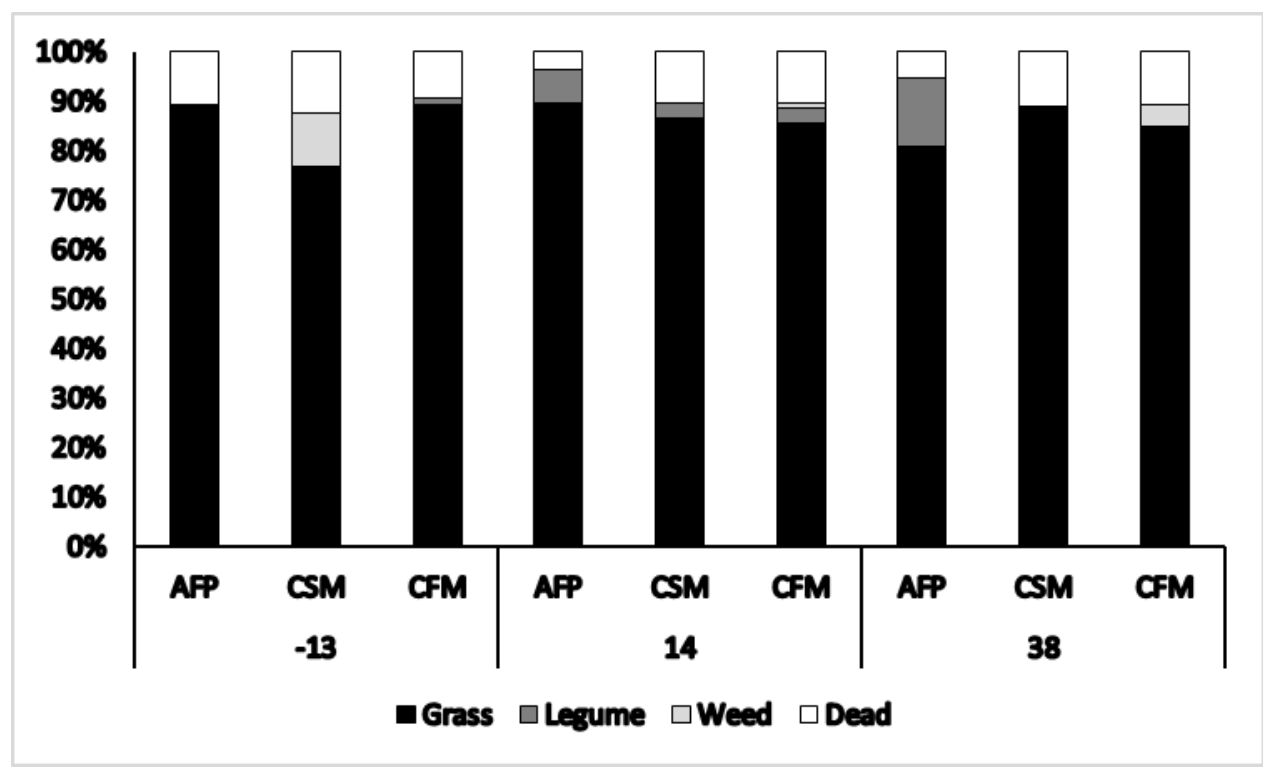

Figure 5. Experiment 1 Botanical Composition. Percentage of grass, legume, weeds and dead material present in samples collected during each month of the experiment. -13 (Aug), 14 (Sept), 30 (Oct). 
A

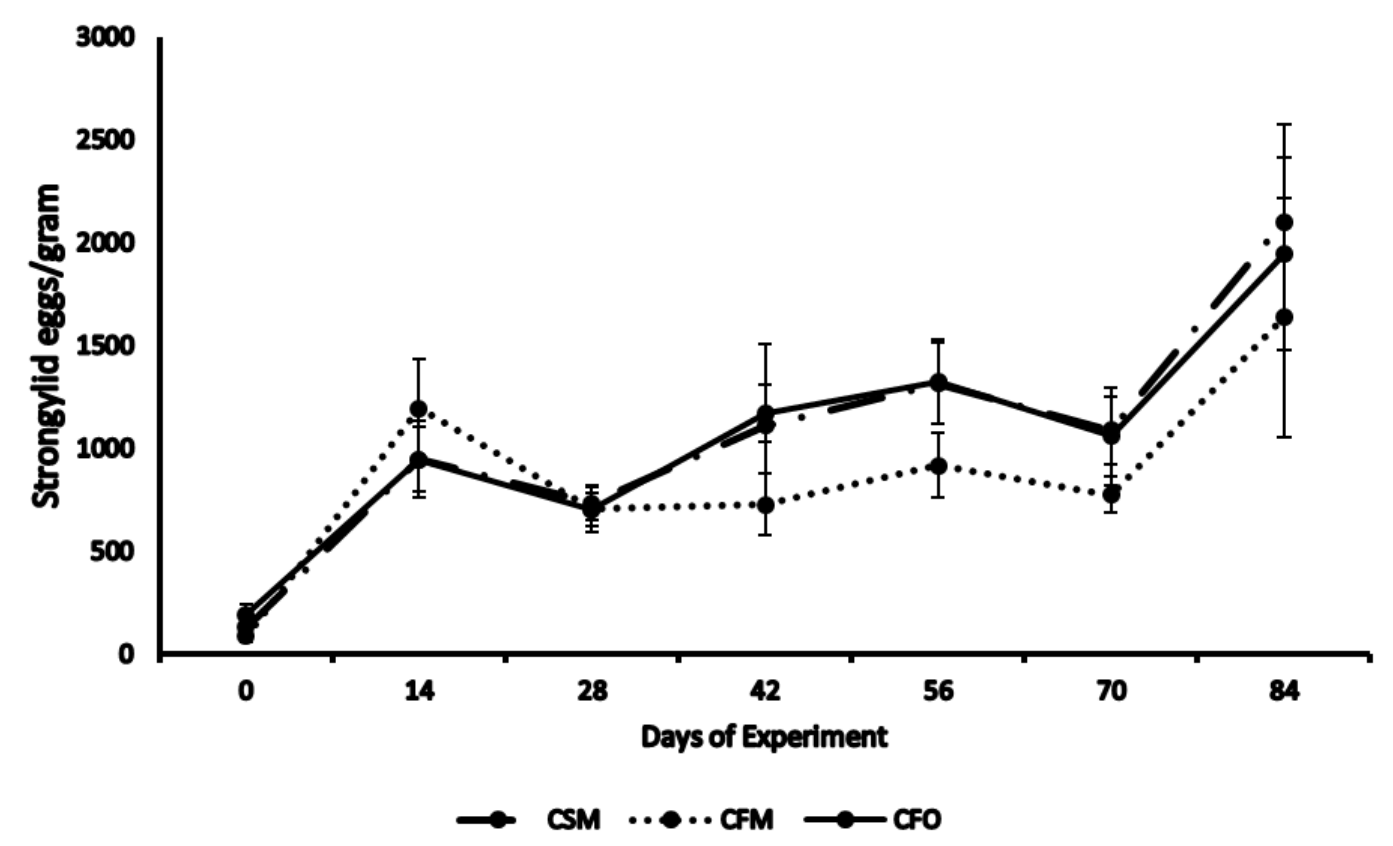

B

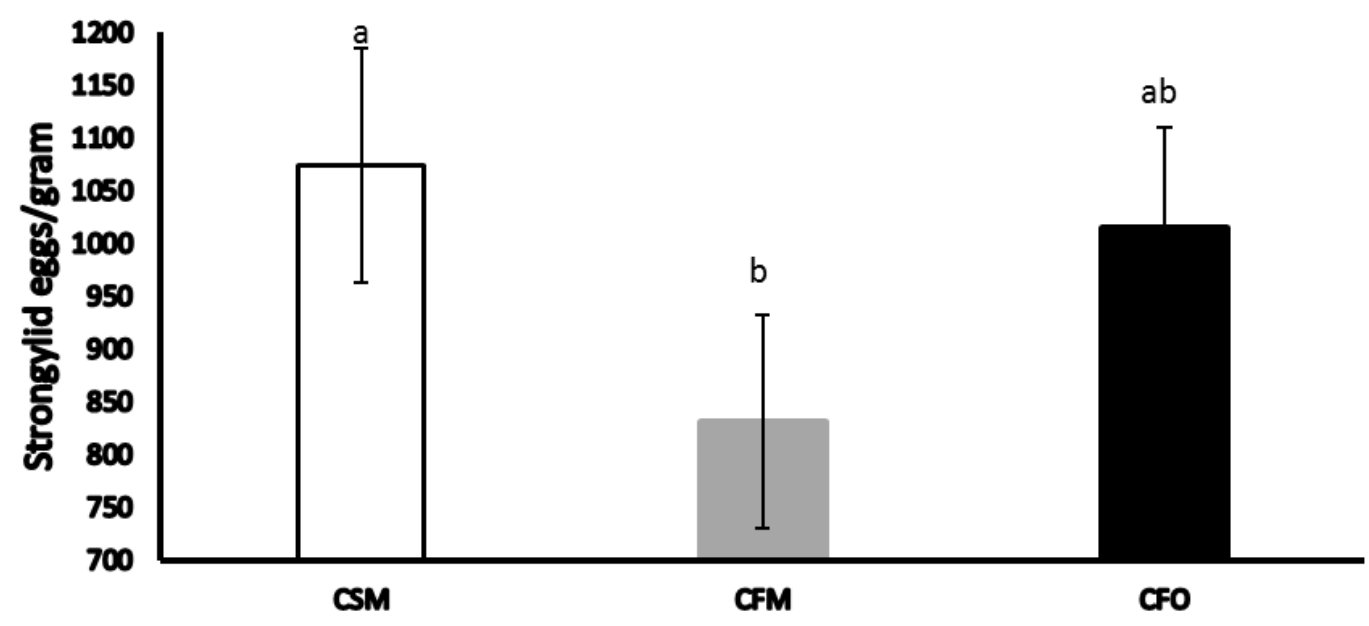

Figure 6. Experiment 2 FEC during the experimental period. Biweekly fecal egg count (FEC) of corn and soybean meal (CSM), corn, soybean and fishmeal (CFM) and corn, soybean meal and fish meal (CFO) during the experimental period (A). Average FEC as a function of CSM, CFM or CFO supplementation (B). Different letters represent significant differences at $P<0.05$. Error bars represent SEM. 
A

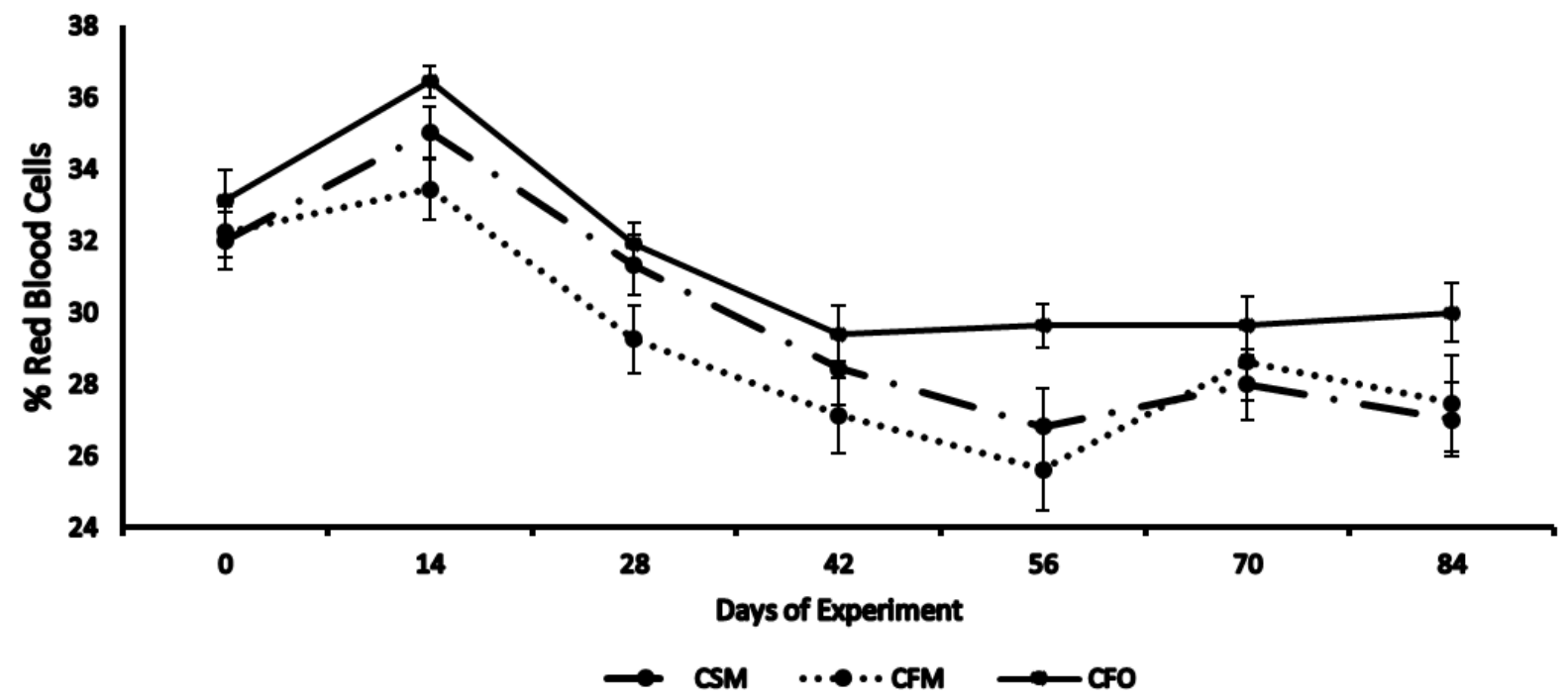

B

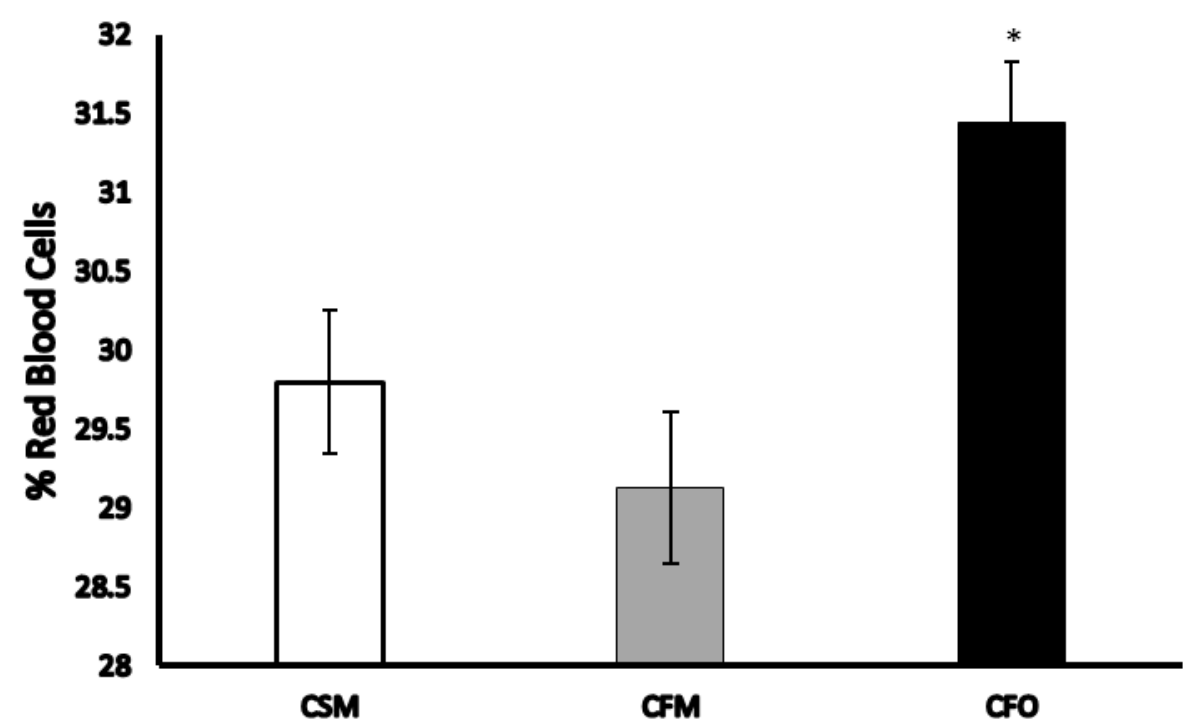

Figure 7. Experiment 2 PCV during the experimental period. Depicts packed cell volume (PCV) at individual sampling dates during experiment (A). Average PCV as a function of corn and soybean meal (CSM), corn, soybean and fish (CFM) or corn, soybean meal and fish oil (CFO) supplementation (B). * represents a significant difference at $P \leq 0.05$. Error bars represent SEM. 
A

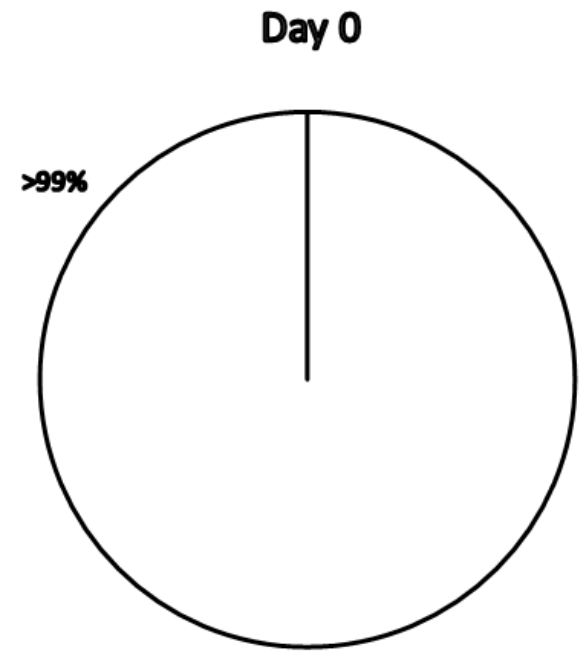

C

Day 56

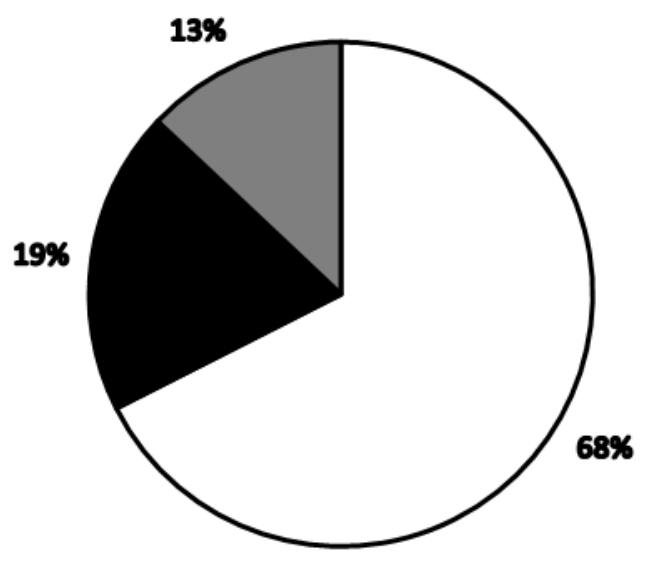

B

\section{Day 28}

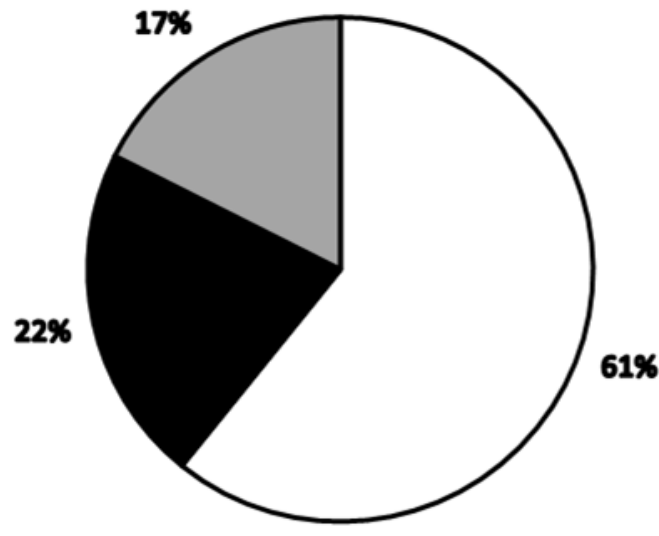

\section{口Haemonchus}

- Telodorsagla

口Trichostrongylus

D

Day 84

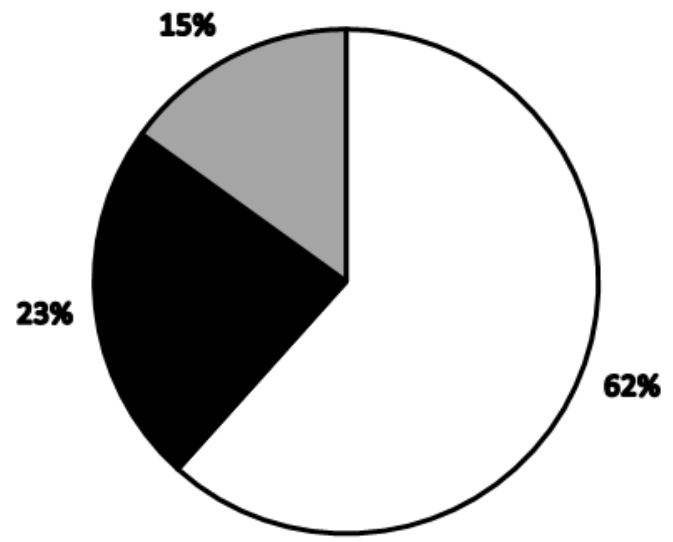

Figure 8. Experiment 2 Larval fecal culture speciation. Feces was collected from each treatment was pooled together to determine larval speciation. A. Day 0. B. Day 28. C. Day 56. D. Day 84. 
A

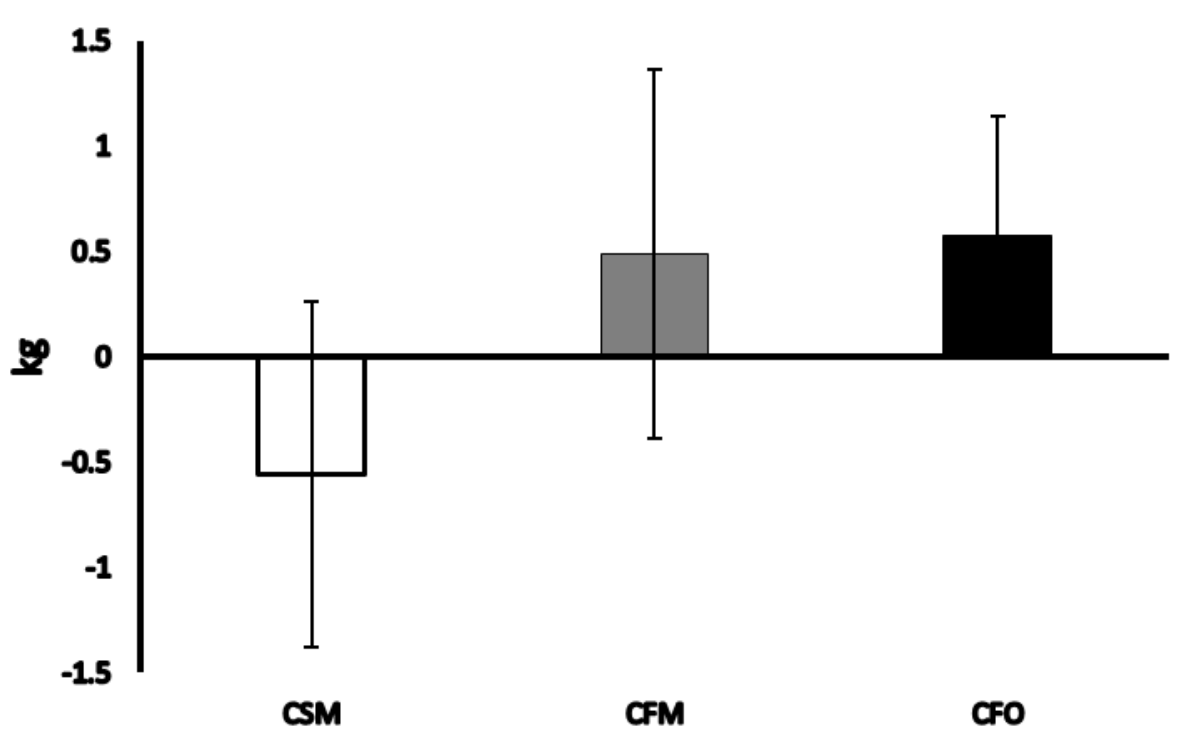

B

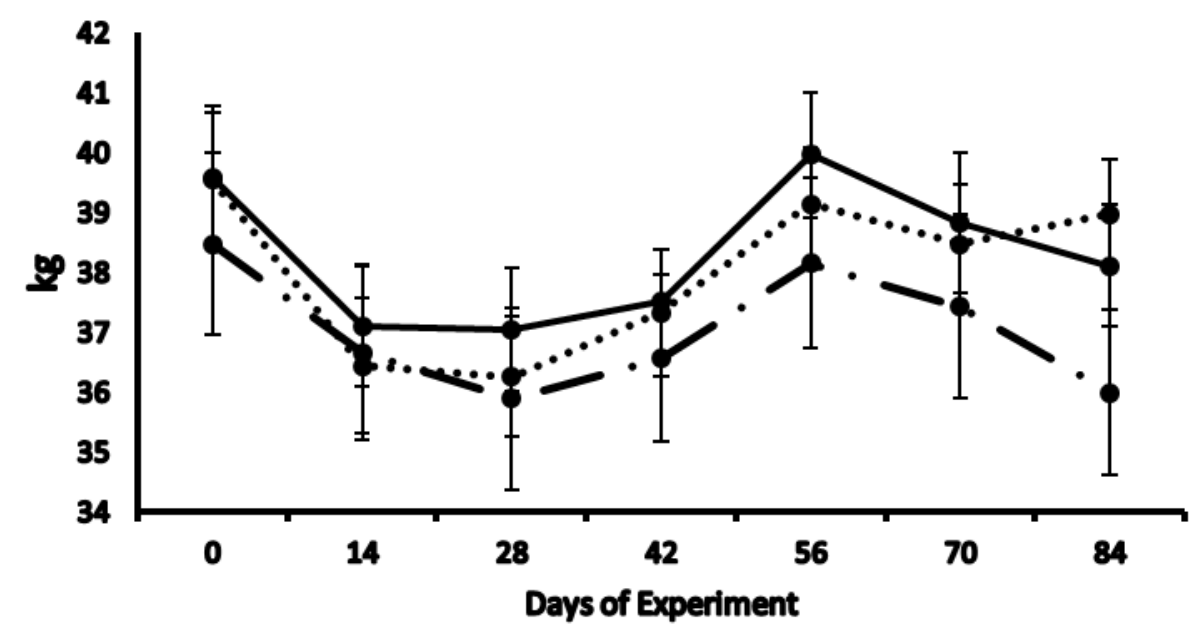

$\longrightarrow \operatorname{CSM} \cdots \bullet \cdot \mathrm{CFM} \longrightarrow \mathrm{CFO}$

Figure 9. Experiment 2 Total gain and weights across the experimental period. Average total gain for corn and soybean meal (CSM), corn, soybean and fishmeal (CFM) and corn, soybean meal and fish oil (CFO) (A). Biweekly weights during the experimental period for CSM, CFM and CFO (B). Error bars represent SEM. 


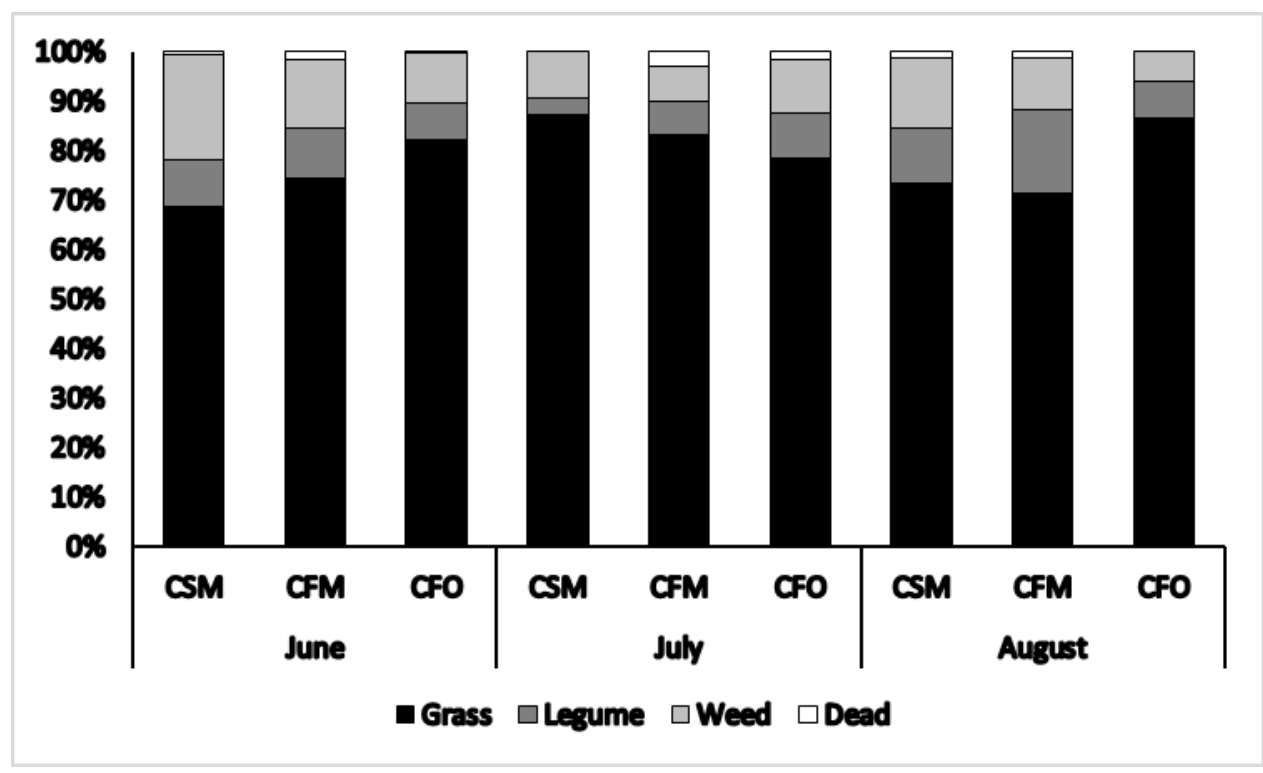

Figure 10. Experiment 2 Botanical Composition. Percentage of grass, legume, weeds and dead material present in samples collected during each month of the experiment. 
Table 1. Experiment 1 Diet Formulation.

\begin{tabular}{lcc}
\hline Ingredient & CSM & CFM \\
\hline Organic Corn & 65 & 70 \\
Organic Soybean Meal & 35 & 21 \\
Fish Meal & 0 & 9 \\
\hline
\end{tabular}

Percentage of feedstuffs in diet formulations of corn, soybean meal (CSM) and corn, soybean and fish meal (CFM). Alfalfa Pellets (AFP) were purchased as a complete feed. 
Table 2. Experiment 1 Chemical analysis of supplements.

\begin{tabular}{llll}
\hline Component & AFP & CSM & CFM \\
\hline DM \% & 92.63 & 88.09 & 88.46 \\
CP \% & 16.51 & 24.11 & 25.79 \\
Ash \% & 8.92 & 3.59 & 5.08 \\
Fat \% & 1.77 & 3.98 & 4.58 \\
TDN \% & 69.61 & 79.38 & 79.69 \\
ADF \% & 27.17 & 4.22 & 3.59 \\
NDF \% & 40.58 & 10.26 & 10.75 \\
\hline All data are reported on a dry matter basis. Alfalfa pellets (AFP). Corn and soybean meal (CSM). \\
Corn, soybean and fish meal (CFM).
\end{tabular}




\section{Table 3. Experiment 1 Herbage Mass.}

\begin{tabular}{ccc} 
& Offered & Disappearance \\
\hline TRT & \multicolumn{2}{c}{ kg.ha-1 } \\
\hline AFP & 4191.60 & 2086.32 \\
CSM & 4192.49 & 2321.72 \\
CFM & 3891.15 & 2014.16
\end{tabular}

Average offered and disappearance of forage mass during the experiment. Alfalfa pellets (AFP). Corn and soybean meal (CSM). Corn, soybean and fish meal (CFM). 
Table 4. Experiment 1 Pasture Analysis.

\begin{tabular}{|c|c|c|c|c|c|c|c|c|}
\hline & Components & DM \% & CP \% & Ash \% & Fat $\%$ & ADF \% & NDF \% & TDN \% \\
\hline & TRT & & & & & & & \\
\hline \multirow{3}{*}{$\begin{array}{c}\text { Day } \\
0\end{array}$} & AFP & 94.27 & 12.76 & 7.95 & 2.68 & 33.41 & 61.47 & 64.46 \\
\hline & CSM & 94.53 & 10.44 & 8.17 & 2.59 & 34.86 & 63.08 & 62.81 \\
\hline & CFM & 94.48 & 12.03 & 7.64 & 1.94 & 34.84 & 62.93 & 62.83 \\
\hline \multirow{3}{*}{$\begin{array}{c}\text { Day } \\
14\end{array}$} & AFP & 93.76 & 23.52 & 9.58 & 2.51 & 25.57 & 51.13 & 73.40 \\
\hline & CSM & 93.76 & 20.06 & 8.86 & 2.47 & 26.14 & 56.71 & 72.75 \\
\hline & CFM & 93.55 & 19.44 & 9.68 & 2.41 & 25.79 & 55.81 & 73.15 \\
\hline \multirow{3}{*}{$\begin{array}{c}\text { Day } \\
28\end{array}$} & AFP & 92.66 & 17.81 & 9.49 & 1.94 & 22.85 & 49.50 & 76.50 \\
\hline & CSM & 91.58 & 21.34 & 9.72 & 3.19 & 22.21 & 51.18 & 77.23 \\
\hline & CFM & 92.39 & 19.70 & 9.33 & 2.63 & 23.39 & 51.73 & 75.89 \\
\hline \multirow{3}{*}{$\begin{array}{c}\text { Day } \\
42\end{array}$} & AFP & 93.00 & 26.66 & 8.63 & 2.42 & 22.67 & 50.39 & 76.71 \\
\hline & CSM & 93.51 & 12.94 & 8.71 & 0.99 & 30.44 & 58.50 & 67.85 \\
\hline & CFM & 93.60 & 15.67 & 8.49 & 2.11 & 31.59 & 62.28 & 66.53 \\
\hline
\end{tabular}

All data are reported on a dry matter basis. Alfalfa pellets (AFP). Corn and soybean meal (CSM). Corn, soybean and fish meal (CFM). 
Table 5. Experiment 2 Diet formulations.

\begin{tabular}{cccc}
\hline Ingredient & CSM & CFM & CFO \\
\hline Organic Corn & 68.1 & 71.9 & 68.3 \\
Organic Soybean Meal & 6.5 & 0 & 0 \\
Soybean Meal & 25.4 & 19.1 & 31.1 \\
Fish Meal & 0 & 9 & 0 \\
Fish Oil & 0 & 0 & 0.6 \\
\hline
\end{tabular}

Percentage of feedstuffs in diet formulations. 
Table 6. Experiment 2 Chemical analysis of supplements.

\begin{tabular}{cccc}
\hline Component & CSM & CFM & CFO \\
\hline DM \% & 87.31 & 87.49 & 86.98 \\
CP \% & 21.82 & 21.67 & 22.02 \\
Ash \% & 3.18 & 4.91 & 3.20 \\
Fat \% & 2.36 & 3.04 & 2.67 \\
TDN \% & 79.36 & 79.95 & 79.59 \\
ADF \% & 4.28 & 3.05 & 3.79 \\
NDF \% & 10.91 & 10.67 & 9.16 \\
\hline
\end{tabular}

All data are reported on a dry matter basis. Corn and soybean meal (CSM). Corn, soybean and fish meal (CFM). Corn, soybean meal and fish oil (CFO). 


\begin{tabular}{llr}
\multirow{2}{*}{ Table 7. } & \multicolumn{2}{c}{ Experiment 2 Herbage Mared } \\
\cline { 2 - 3 } & Offered & \multicolumn{2}{c}{ Disappearance } \\
\hline TRT & \multicolumn{2}{c}{ kg.ha-1 } \\
\hline CSM & 4834.13 & 3435.00 \\
CFM & 4887.36 & 3484.57 \\
CFO & 4750.29 & 3403.39 \\
\hline
\end{tabular}

Average offered and disappearance of forage mass during the experiment. Corn and soybean meal (CSM). Corn, soybean and fish meal (CFM). Corn, soybean meal and fish oil (CFO). 
Table 8. Experiment 2 Pasture Analysis.

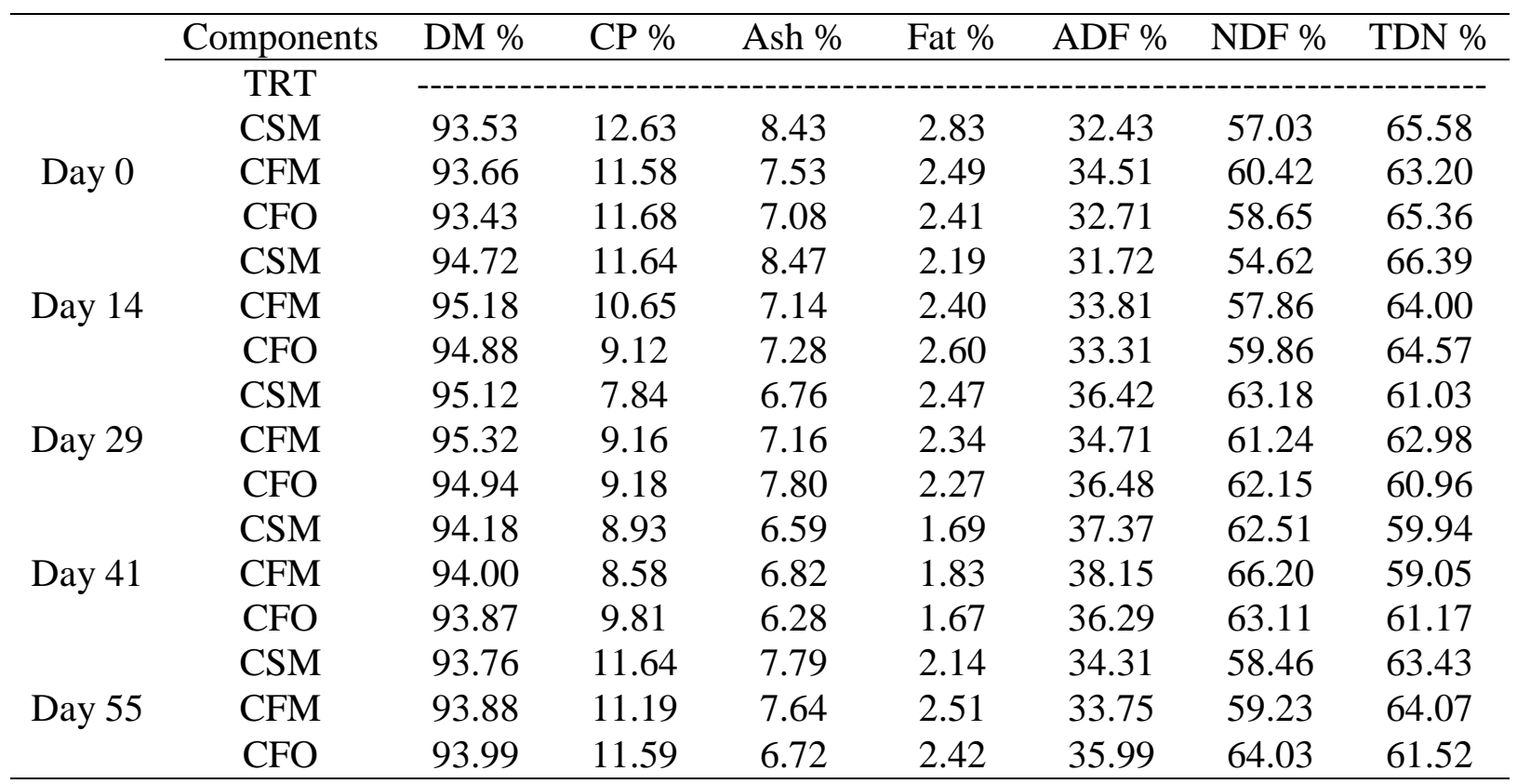

All data are reported on a dry matter basis. Corn and soybean meal (CSM). Corn, soybean and fish meal (CFM). Corn, soybean meal and fish oil (CFO). 


\section{Literature Cited}

2014). About: Barbervax. Retrieved November 23, 2014.

(2014). How to Use: Barbervax. Retrieved November 23, 2014.

Abaye, A. O., V. G. Allen, et al. (1997). Grazing Sheep and Cattle Together or Separately: Effect on Soils and Plants. Agron. J. 89(3): 380-386.

Abbott, K. A. and I. J. McFarland (1991). Trichostrongylus axei infection as a cause of deaths and loss of weight in sheep. Aus. Vet. J. 68: 368-369.

Athanasiadou, S., I. Kyriazakies, F. Jackson, R. L. Coop (2001). Direct anthelmintic effects of condensed tannins towards different gastrointestinal nematodes of sheep: in vitro and in vivo studies. Vet. Parasitol. 99(3): 205-219.

Bang, K. S., A. S. Familton, et al. (1990). Effect of copper oxide wire particle treatment on establishment of major gastrointestinal nematodes in lambs. Res. Vet. Sci. 49: 132-137.

Bassetto, C. C., M. R. L. Silva, et al. (2014). Vaccination of grazing calves with antigens from the intestinal membranes of Haemonchus contortus: effects against natural challenge with Haemonchus placei and Haemonchus similis. Int. J. Parasitol. 44(10): 697-702.

Bath, G. F. (1996). The FAMACHA Ovine Anemia Guide to assist with the control of haemonchosis in sheep and goats. 7th Annual Congress of the Livestock Health and Production Group of the South African Veterinary Association, Port Elizabeth, South Africa.

Bishop, S. C. and C. A. Morris (2007). Genetics of disease resistance in sheep and goats. Sm. Rum. Res. 70(1): 48-59.

Bowman, D. D. (2003). Georgis' Parasitology for Veterinarians. St. Louis, Missouri, Saunders Elsevier.

Bown, M. D., D. P. Poppi, et al. (1991). Nitrogen transactions along the digestive tract of lambs concurrently infected with Trichostrongylus colubriformis and Ostertagia circumcinta. British J. Nu. 66: 237-249.

Bremner, K. C. (1969). Pathogenic factors in experimental bovine oesophagosomosis. III. Demonstration of protein-losing enteropathy with Cr-albumin. Exp. Parasitol. 64(Suppl.): 197198.

Brown, M. D., D. P. Poppi, et al. (1991). "The effect of post-ruminal infusion of protein or energy on the pathophysiology of Trichostrongylus colubriformis infection and body composition in lambs." Aus. J. Agri. Res. 42(2): 253-267.

Bunch, T. D., R. C. Evans, et al. (2004). Feed efficiency, growth rates, carcass evaluation, cholesterol level and sensory evaluation of lamb of various hair and wool sheep and their crosses. Sm. Rum. Res. 52(3): 239-245. 
Burke, J. M., J. E. Miller, et al. (2004). Effect of copper oxide wire particles dosage and feed supplement level and Haemonchus contortus infection in lambs. Vet. Parasitol. 123(3-4): 235243.

Burke, J. M., J. E. Miller, et al. (2009). Impact of rotational grazing on management of gastrointestinal nematodes in weaned lambs. Vet. Parasitol. 163(1-2): 67-72.

Chartier, C., E. Etter, et al. (2000). Efficacy of Copper Oxide Needles for the Control of Nematode Parasites in Dairy Goats. Vet. Res. Comm. 24: 289-399.

Cockett, N. S. (2005). Use of QTL to Determine Parasite Resistance in Sheep. Annual Meeting of American Society of Animal Scientists, Cincinnati, Ohio, USA.

Colditz, I. G. (2003). Metabolic effects of immune activation during gastrointestinal parasitism in sheep. Aus. J. Exper. Agri. 43: 1437-1443.

Coles, G. C. (2005). Anthelmintic resistance - looking to the future: a UK perspective. Res. Vet. Sci. 78(2): 99-108.

Colvin, A. F., S. W. Walkden-Brown, et al. (2008). Intensive rotational grazing assists control of gastrointestinal nematodosis of sheep in a cool temperate environment with summer dominant rainfall. Vet. Parasitol. 153(1-2): 108-120.

Coop, R. L., J. F. Huntley, W. D. Smith (1995). Effect of dietary protein supplementation on the development of immunity to Ostertagia circumcincta in growing lambs. Res. Vet. Sci. 59: 24-25.

Coop, R. L. and P. H. Holmes (1996). Nutrition and parasite interaction. Int. J. Parasitol. 26(8-9): 951962.

Coop, R. L. and I. Kyriazakis (1999). Nutrition - parasite interaction. Vet. Parasitol. 84(3-4): 187-204.

Courtney, C. H., C. F. Parker, et al. (1985). Resistance of nonlambing exotic and domestic ewes to naturally acquired gastrointestinal nematodes. Int. J. Parasitol. 15(3): 239-243.

Dargie, J. D., Ed. (1975). Applications of radioisotope techniques to study red cell and plasma in helminth diseases of sheep. Pathogenic Processes in Parasitic Infection. Oxford, Blackwell Scientific Publications.

Datta, F. U., J. V. Nolan, et al. (1999). Long-term effects of short-term provisions of protein-enriched diets on resistance to nematode infection, and live-weight gain and wool growth in sheep. Int. J. Parasitol. 29: 479-488.

Dewey, D. W. (1977). An effective method for the administration of trace amounts of copper to ruminants. Seach 8: 326-327. 
Drudge, J. H., S. E. Leland, et al. (1957). Strain variation in the response of sheep nematodes to the action of phenothiazine. II. Studies on pure infections of Haemonchus contortus. Am. J. Vet. Res. 18(67): 317-325.

Drudge, J. H., J. Szanto, et al. (1964). Field Studies on Parasite Control in Sheep: Comparison of Thiabendazole, Ruelene, and Phenothiazine. Am. J. Vet. Res. 25: 1512.

Farthing, M. J. G., A. B. Ballinger, et al. (2001). Anorexia and cytokines in the acute phase response to infection. Philadelphia, USA, Lippincott, Williams and Wilkins.

Gamble, H. R. and A. M. Zajac (1992). Resistance of St. Croix lambs to Haemonchus contortus in experimentally and naturally acquired infections. Vet. Parasitol. 41(3-4): 211-225.

Grimble, R. F. (2002). Sulphur amino acids, glutathione and immune function. Wallingford, UK, CABI Publishing.

Herd, R. P., R. H. Streitel, et al. (1983). Control of periparturient rise in worm counts of lambing ewes. J. Am. Vet. Med. Assoc. 182(4): 375.

Holmes, P. H., J. M. Maclean (1971). The pathophysiology of ovine ostertagiasis: water balance and turnover studies. Res. Vet. Sci. 12: 381-383.

Hoste, H. and J. F. J. Torres-Acosta (2011). Non chemical control of helminths in ruminants: Adapting solutions for changing worms in a changing world. Vet. Parasitol. 180(1-2): 144-154.

Howell, S. B., J. M. Burke, et al. (2008). Prevalence of anthelmintic resistance on sheep and goat farms in the Southeastern United States. J. Am. Vet. Med. Assoc. 233(12): 1912-1919.

Jones, W. O. and L. E. A. Symons (1982). Protein synthesis in the whole body, liver, skeletal muscle, skeletal muscle and kidney cortex of lambs infected by the nematode Trichostrongylus colubriformis. I. J. Parasitol. 12: 295-301.

Kalra, E. K. (2003). Nutraceutical - definition and introduction. Aaps Pharmsci 5(3): 27-28.

Kaminsky, R., P. Ducray, et al (2008). A new class of anthelmintics effective against drug-resistant nematodes. Nature 452: 176-180.

Kaplan, R. M. (2004). Drug resistance in nematodes of veterinary importance: a status report. Trends Parasitol. 20(10): 477-481.

Kaplan, R. M., J. M. Burke, et al. (2004). Validation of the FAMACHA eye color chart for detecting clinical anemia in sheep and goats on farms in the southern United States. Vet. Parasitol. 123(12): 105-120. 
Ketzis, J. K., A. Taylor, D. D. Bowman, D. L. Brown, L. D. Warnick, H. N. Erb (2002). Chenopodium ambrosioides and its essential oil as treatments for Haemonchus contortus and mixed adultnematode infections in goats. Sm. Rum. Res. 44(3): 193-200.

Kumar, N., T. K. S. Rao, et al. (2013). Internal parasite management in grazing livestock. Journal of Para. Dis. 37(2): 151-157.

Lange, K. C., D. D. Olcott, et al. (2006). Effect of sericea lespedeza (Lespedeza cuneata) fed as hay on natural and experimental Haemonchus contortus infections in lambs. Vet. Parasitol. 141(3-4): 273-278.

Larsen, M., P. Nansen, et al. (1992). In vivo passage of nematophagous fungi selected for biocontrol of parasitic nematodes in ruminants. J. Helminthol. 66: 137-141.

Le Jambre, L. F., J. H. Gill, et al. (2000). Inheritance of avermectin resistance in Haemonchus contortus. I. J. Parasitol. 30(1): 105-111.

Lindsay, J. R., J. P. Hogan, et al. (1980). The digestion of protein from forage diets in the small intestines of the sheep. Aus. J. Agri. Res. 31: 589-600.

MacRae, J. C. (1993). Metabolic consequences of intestinal parasitism. Proceedings of the Nutrition Society 52: 01 .

Marley, C. L., R. Cook, et al. (2003). The effect of birdsfoot trefoil (Lotus corniculatus) and chicory (Cichorium intybus) on parasite intensities and performance of lambs naturally infected with helminth parasites. Vet. Parasitol. 112(1-2): 147-155.

Marley, C. L., M. D. Fraser, et al. (2006). The effect of mixed or sequential grazing of cattle and sheep on the faecal egg counts and growth rates of weaned lambs when treated with anthelmintics. Vet. Parasitol. 142(1-2): 134-141.

Martin, R. J. (1997). Modes of Action of Anthelmintic Drugs. The Vet. J. 154: 11-34

Mcleod, R. S. (1995). Costs of Major Parasites to the Australian Livestock Industries. Int. J. Parasitol. 25(11): 1363-1367.

McNeilly, T. N., E. Devaney, et al. (2009). Teladorsagia circumcincta in the sheep abomasum: defining the role of dendritic cells in T cell regulation and protective immunity. Para. Immunol. 31(7): 347-356.

Min, B. R., S. P. Hart (2003). Tannins for suppression of internal parasites. J. Ani. Sci. 81(E. Suppl. 2): E201-E109.

Min, B. R., W. E. Pomroy, S. P. Hart, T. Sahlu (2004). The effect of short-term consumption of a forage containing condensed tannins on gastro-intestinal nematode parasite infections in grazing wether goats. Sm. Rum. Res. 51(3): 279-283. 
National Research Council. (2007). Nutrient Requirements of Small Ruminants: sheep, goats, cervids and New World camelids. Washington, DC, The National Academies Press.

O'Callaghan, M. G., R. R. Martin, et al. (2008). A natural infection of sheep with Ostertagia osteragi. Aus. Vet. J. 69(1): 19-20.

Paolini, V., J. P. Bergeaud, et al. (2003). Effect of condensed tannins on goats experimentally infected with Haemonchus contortus. Vet. Parasitol. 113(3-4): 253-261.

Pena, M. T., J. E. Miller, et al. (2002). Evaluation of Duddingtonia flagrans in reducing infecting larvae of Haemonchus contortus in feces of sheep. Vet. Parasitol. 103(3): 259-265.

Poppi, D. P., J. C. MacRae, et al. (1986). Nitrogen transaction in the digestive tract of lambs exposed to the intestinal parasite Trichostrongylus colubriformis. British J. Nut. 55: 593-602.

Rose, J. H. (1963). Observations on the free-living stages of the stomach worm Haemonchus contortus. Parasitol. 53(3-4): 469-481.

Rowe, J. B., E. M. Abbott, J. D. Dargie, P. H. Holmes (1982). The effect of haemonchosis and blood loss into the abomasum on $\mathrm{N}$ digestion in sheep. Nut. Soc.

Sackett, D. H. (2005). Assessing the Economic Cost of Endemic Disease on the Profitability of Australian Beef Cattle and Sheep Producers. Sydney, Meat and Livestock Australia.

Scott, I. e. a. (2013). Lack of efficacy of monepantel against Teladorsagia circumcincta and Trichostrongylus columbriformis. Vet. Parasitol. 1998(1-2): 166-171.

Soli, F., T. H. Terrill, et al. (2010). Efficacy of copper oxide wire particles against gastrointestinal nematodes in sheep and goats. Vet. Parasitol. 168(1-2): 93-96.

Squires, J. M., J. G. Foster, D. S. Lindsay, D. L. Caudell, A. M. Zajac (1995). Efficacy of an orange oil emulsion as an anthelmintic against Haemonchus contortus in gerbils (Meriones unguiculatus) and in sheep. Vet. Parasitol. 172(1-2): 95-99.

Strain, S. A. J. and M. J. Stear (2001). The influence of protein supplementation on the immune response to Haemonchus contortus. Paras. Immunol. 23: 527-531.

Suttle, N. F. (1987). Safety and effectiveness of cupric oxide particles for increasing liver copper stores in sheep. Re. Vet. Sci. 42(2): 219-223.

Sykes, A. R. and R. L. Coop (1976). Intake and utilization of food by growing sheep with parasitic damage to the small intestine caused by daily dosing with Trichstrongylus colubriformis larvae. J. Agric. Sci. 86: 507-515. 
Sykes, A. R. and R. L. Coop (1977). Intake and utilization of food by growing sheep with abomasal damage caused by daily dosing with Ostertagia circumcincta larvae. J. Agric. Sci. 88: 671-677.

Symons, L. E. A. (1985). Anorexia; occurrence, pathophysiology, pathophysiology and possible causes in parasitic infection. Advances Parasitol. 24: 103-133.

Terrill, T. H., M. Larsen, et al. (2004). Capability of the nematode-trapping fungus Duddingtonia flagrans to reduce infective larvae of gastrointestinal nematodes in goat feces in the southeastern United States: dose titration and dose time interval studies. Vet. Parasitol. 120(4): 285-296.

Thamsborg, S. M., R. J. Jorgensen, et al. (1996). The influence of stocking rate on gastrointestinal nematode infection of sheep over a 2-year grazing period. Vet. Parasitol. 67(3-4): 207-224.

Torres-Acosta, J. F. J. and H. Hoste (2008). Alternative or improved methods to limit gastro-intestinal parasitism in grazing sheep and goats. Sm. Rum. Res. 77(2-3): 159-173.

Torres-Acosta, J. F. J., C. A. Sandoval-Castro, et al. (2012). Nutritional manipulation of sheep and goats for the control of gastrointestinal nematodes under hot humid and subhumid tropical conditions. S. Rum. Res. 103(1): 28-40.

USDA (2001). Part II: Reference of Sheep Health in the United States. In: USDA-APHIS." Fort Collins, Co.

van Houtert, M. F. J., I. A. Barger, et al. (1995). Effects of dietary protein intake on responses of young sheep to infection with Trichostronglyus colubriformis. Vet. Parasitol. 56: 163-180.

Van Wyk, J. A. (2001). Refugia- overlooked as perhaps the most potent factor concerning the development of anthelmintic resistance. Onderstepoort J. Vet. Res. 68: 49.

Vlassoff, A. and P. B. McKenna (1994). Nematode parasites of economic importance in sheep in New Zealand. New Zealand J. Zool. 21(1): 1-8.

Wallace, D. S., K. Bairden, et al. (1995). Influence of supplementation with dietary soyabean meal on resistance to haemonchosis in Hampshire down lambs. Res. Vet. Sci. 58(3): 232-237.

Waller, P. J. and S. M. Thamsborg (2004). Nematode control in 'green' ruminant production systems. Trends Parasitol. 20(10): 493-497.

Whitelaw, A., A. R. Fawcett, et al. (1982). Cupric oxide needles in the prevention of swayback. Vet. Rec. 110(22): 522.

Wildeus, S. (1997). Hair sheep genetic resources and their contribution to diversified small ruminant production in the United States. J. Anim. Sci. 75(3): 630-640.

Woolaston, R. R. and L. R. Piper (1996). Selection of Merino sheep for resistance to Haemonchus contortus: genetic variation. Anim. Sci. 62(03): 451-460. 